\title{
PACAP and VIP modulate LPS-induced microglial activation and trigger distinct phenotypic changes in murine BV2 micro- glial cells
}

\author{
Jocelyn Karunia', Aram Niaz', Mawj Mandwie ${ }^{1}$, Sarah Thomas Broome ${ }^{1}$, Kevin A. Keay ${ }^{2}$, James A. Waschek ${ }^{3}$, \\ Ghaith Al-Badri' ${ }^{1}$ and Alessandro Castorina ${ }^{1,2 *}$ \\ 1 Laboratory of Cellular and Molecular Neuroscience (LCMN), School of Life Sciences, Faculty of Science, \\ University of Technology Sydney, 2007, NSW, Sydney, Australia \\ 2 School of Medical Science, [Neuroscience] and Brain and Mind Centre, The University of Sydney, 2006 \\ NSW, Sydney, Australia \\ 3 Intellectual Development and Disabilities Research Centre, Semel Institute for Neuroscience and Human \\ Behaviour/Neuropsychiatric Institute, David Geffen School of Medicine, University of California-Los Ange- \\ les, Los Angeles, California 90095 \\ * Correspondence: Alessandro.castorina@uts.edu.au
}

\begin{abstract}
Pituitary adenylate cyclase-activating polypeptide (PACAP) and vasoactive intestinal peptide (VIP) are two structurally-related immunosuppressive peptides. However, the underlying mechanisms through which these peptides regulate microglial activity are not fully understood. Using lipopolysaccharide (LPS) to induce an inflammatory challenge, we tested whether PACAP or VIP differentially affected microglial activation, morphology and cell migration. We found that both peptides attenuated LPS-induced expression of the microglial activation markers Iba1 and iNOS (\#\#\# $<0.001)$, as well as the pro-inflammatory mediators $I L-1 \beta, I L-6$, Itgam and CD68 (\#\#\# $<0.001)$. In contrast, treatment with PACAP or VIP exerted distinct effects on microglial morphology and migration. PACAP reversed LPS-induced soma enlargement and increased the percentage of smallsized, rounded cells (54.09\% vs $12.05 \%$ in LPS-treated cells), whereas VIP promoted a phenotypic shift towards cell subpopulations with mid-sized, spindle-shaped soma (48.41\% vs $31.36 \%$ in LPStreated). Additionally, PACAP was more efficient than VIP in restoring LPS-induced impairment of cell migration and the expression of urokinase plasminogen activator (uPA) in BV2 cells compared with VIP. These results suggest that whilst both PACAP and VIP exert similar immunosuppressive effects in activated BV2 microglia, each peptide triggers distinctive shifts towards phenotypes of differing morphologies and with differing migration capacities.
\end{abstract}

Keywords: microglial activation; PACAP; VIP; morphological analyses; BV2; inflammatory markers; GFAP; Iba1

\section{Introduction}

Microglia are central nervous system (CNS) resident macrophage-like cells whose activities are highly relevant in neuroimmune interactions, especially after immune insult or trauma to the brain [1,2]. In particular, these cells play important roles in modulating both the innate and adaptive immune responses through their ability to produce and secrete several inflammatory mediators following polarization, via various toll-like receptors (TLRs), (i.e., TLRs 1-9) [3,4]. In the CNS, the process of neurodegeneration is characterised by morphological, metabolic and functional neuronal changes that result in premature, progressive, and chronic, neural cell loss [5-8]. It has been recently recognized that uncontrolled and long-lasting neuroinflammation might be responsible for the progressive CNS degeneration seen in many neurological conditions $[9,10]$. A compelling hypothesis is that microglial cells play a particularly important role in the aetiology and/or progression of neurodegenerative and autoimmune diseases [2,11-18]. Within the healthy 
CNS, microglia are said to exist in a "resting" state. In this state, their morphology in tissue sections appears as a cell with a small soma and ramified processes. In fact, the smaller processes "filopodia" are motile and appear to survey continuously the CNS parenchyma [19]. However, on interacting with invading pathogens or after CNS injury, microglial cells transition to an activated, or polarised state by undergoing a series of neurochemical and morphological changes, including the enlargement and flattening of the soma and the shortening and thickening of the cellular processes [20]. At the biochemical level, microglial cells can be activated to either a pro-inflammatory M1 state, or an anti-inflammatory M2 state [21]. When cells are in the pro-inflammatory M1 state, they produce and secrete several pro-inflammatory cytokines including tumour necrosis factor (TNF), interleukin (IL) $-1 \beta$ and IL-6, whereas if cells switch to the M2 state they aid in controlling the inflammatory microenvironment by secreting anti-inflammatory cytokines and growth factors, thereby inhibiting inflammation and promoting repair $[1,8,22]$. It is noteworthy that the production of cells with the M1 phenotype is a necessary step in CNS repair, regardless of their established associations with neurodegeneration [23]. In fact, M1 polarisation is beneficial in the short-term for the survival of neurons, where microglia are able to actively phagocytose cell debris and recruit immune cells to the inflamed CNS compartment. However, a prompt shift to the M2 phenotype, or a return to the resting state is required to prevent excessive and prolonged M1 activation [21,24]. There are a number of proposed mechanisms that contribute to the initial activation of the M1 phenotype, including microglial recognition of damage-associated molecular patterns (DAMPs) or pathogen-associated molecular patterns (PAMPs) [8].

To date, the regulatory mechanisms underlying the control of microglial behaviours during inflammation are not fully understood [25]. Multiple studies have shown that uncontrolled M1 microglial activation leads to detrimental effects in the CNS [14,25-28]. Unfortunately, there have been no treatments identified that are able to halt or prevent persistent microglial activation, and almost all attempts to do this have been unsuccessful.

The neuropeptides PACAP and VIP have gained more interest within the CNS due to their wide range of neuroprotective functions as well as their widespread CNS localisation [29-36]. PACAP and VIP exert their biological effects through their interactions with three G-protein coupled receptors (GPCRs): PAC1, VPAC1 and VPAC2 [37]. PACAP binds to PAC1 with about 100-fold higher affinity than VIP and both peptides have equally high affinities for both VPAC1 and VPAC2 [38]. PACAP and VIP receptors are expressed in microglia, astrocytes, brain endothelial cells, macrophages, oligodendrocyte progenitors and Schwann cells, and thus are able to elicit cell-specific biological functions in both the CNS and the periphery [30,31,33,35,39-42].

In addition to their well-known neuro- and glio-protective functions, at nanomolar concentrations PACAP and VIP are also able to modulate immunological function [43-46]. Each peptide has been shown to inhibit pro-inflammatory cytokines and neurotoxic factors secreted by activated microglia in a model of PD and brain injury $[47,48]$. Also, in an in-vivo model of brain trauma, VIP inhibited microglial-derived pro-inflammatory cytokines, including IL-1 $\beta$ [39].

While many of the protective activities of PACAP and VIP on neurons and glial cells have been identified $[32,36,49]$, the question of whether there are any differences in the way microglial cells respond to PACAP or VIP to elicit their anti-inflammatory roles has not been fully explored. To address this issue, in the current study we used BV2 cells, an immortalized, murine microglial cell line sharing several biochemical properties with primary microglia [50]. BV2 cells were activated in vitro using LPS, and cells were administered with either PACAP or VIP at concentrations previously identified to be effective, this was followed by biochemical, morphological analyses and assessment of cell migration. Our approach allowed us to reveal biological differences in the cellular response to each of these neuropeptides, in addition to demonstrating that each of the peptides possess robust anti-inflammatory properties. 


\section{Results}

2.1 Dose-response effects of LPS on the mRNA expression of pro-inflammatory cytokines and microglia activation markers in BV2 cells

In order to establish the concentration of LPS most suitable for triggering a robust inflammatory response in the BV2 microglial cell line, we conducted real-time quantitative polymerase chain reaction (qPCR) to measure the gene expression of a panel of proinflammatory mediators (IL-1 $\beta$, IL-6, Itgam, AIF1, Adgre1, CD68 and NOS2) and the antiinflammatory gene $I L-10$ at increasing concentrations of LPS $(0.1,1$ and $10 \mu \mathrm{g} / \mathrm{ml})$. When LPS was used at a concentration of $0.1 \mu \mathrm{g} / \mathrm{ml}$, there was only a significant increase in $I L-1 \beta$ $\left(\mathrm{F}(3,17)=78.95,{ }^{*} \mathrm{p}<0.05\right), \operatorname{Itgam}\left(\mathrm{F}(3,19)=5.373,{ }^{*} \mathrm{p}<0.05\right)$, Adgre1 $\left(\mathrm{F}(3,17)=18.54,{ }^{* *} \mathrm{p}<0.01\right)$ and $C D 68\left(\mathrm{~F}(3,20)=16.54,{ }^{*} \mathrm{p}<0.05\right)$ (Fig. 1a, 1d, 1f and 1g). While the remaining genes examined, IL-6, IL-10, AIF1 and NOS2 were unaffected ( $>>0.05$, Fig. 1b-c, 1e and $\mathbf{1 h}$ ). At $1.0 \mu \mathrm{g} / \mathrm{ml}$, LPS significantly increased both $I L-1 \beta\left({ }^{* * *} \mathrm{p}<0.001\right), \operatorname{IL}-6(\mathrm{~F} \quad(3,19)=245.2$, $\left.{ }^{* * *} \mathrm{p}<0.001\right)$, Itgam $\left({ }^{* *} \mathrm{p}<0.01\right), \operatorname{AIF1}\left(\mathrm{F}(3,16)=5.925,{ }^{*} \mathrm{p}<0.05\right)$, Adgre1 $\left({ }^{* * *} \mathrm{p}<0.001\right)$, CD68 $\left({ }^{* * *} \mathrm{p}<0.001\right)$ and NOS2 $\left(\mathrm{F}(3,15)=67.85,{ }^{* * *} \mathrm{p}<0.001\right)$ (see Fig. 1a, 1d-h). Whereas, the mRNA expression levels of anti-inflammatory IL-10, were unaffected (Fig. 1c, $p>0.05$ ). At the highest concentration tested $\left(10 \mu \mathrm{g} / \mathrm{ml}\right.$ LPS), IL-1 $\left.\left(^{* * *} \mathrm{p}<0.001\right), I L-6{ }^{* * *} \mathrm{p}<0.001\right), I L-10$ (F $\left.(3,15)=3.827,{ }^{*} \mathrm{p}<0.05\right), \operatorname{Adgre1}\left({ }^{* * *} \mathrm{p}<0.001\right), C D 68\left(^{* *} \mathrm{p}<0.01\right)$ and NOS2 $\left({ }^{* * *} \mathrm{p}<0.001\right)$ were all increased significantly when compared to controls (Fig. 1a-c and 1f-h). No significant changes were observed in the levels of Itgam and AIF1 (Fig. 1d and 1e, p>0.05).

A

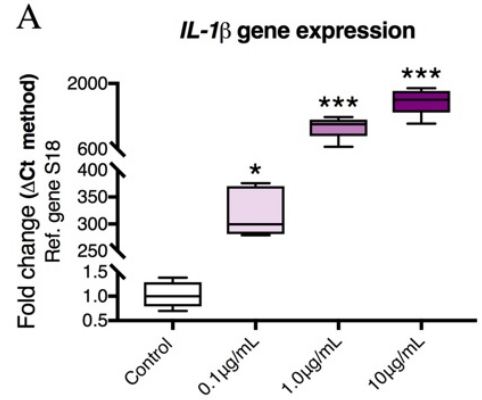

D

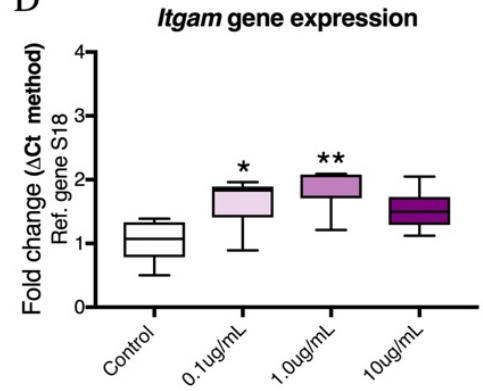

$\circ$

CD68 gene expression

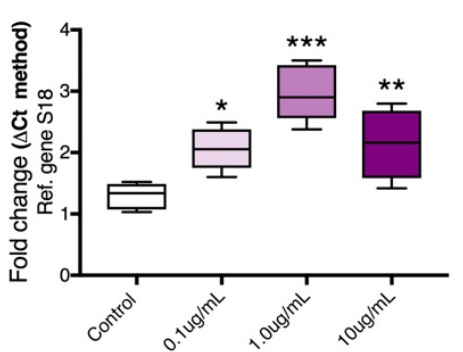

B

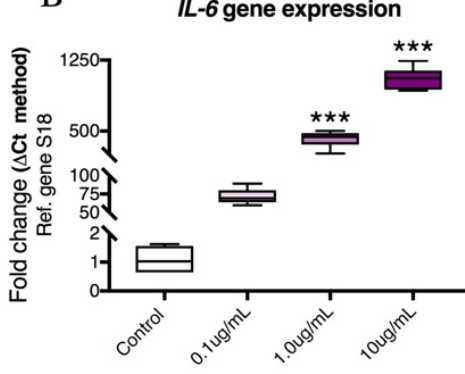

$\mathrm{E}$

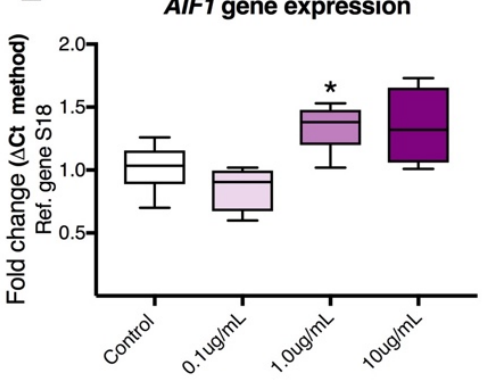

$\mathrm{H}$

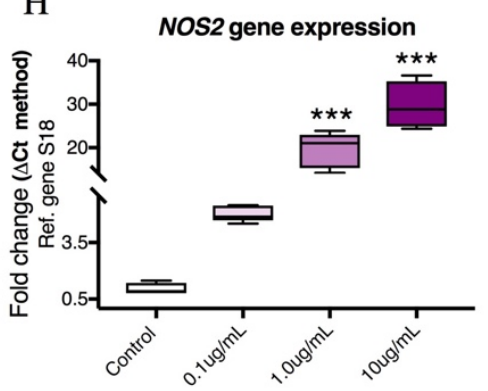

C IL-10 gene expression

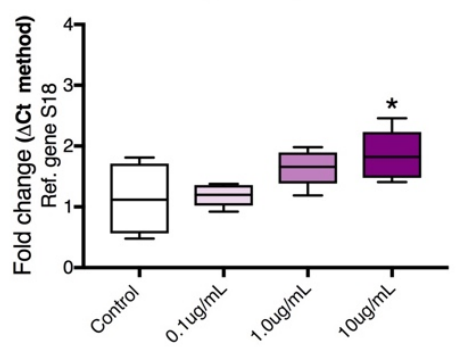

F

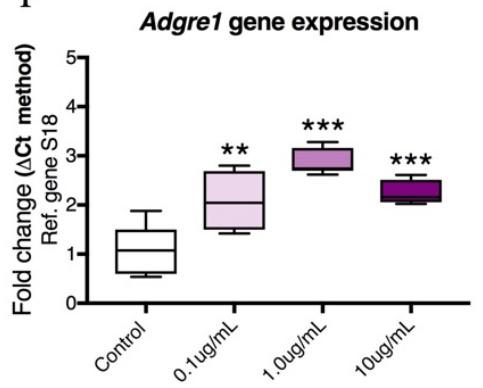

Figure 1. LPS titration experiments showing dose dependent changes in mRNA expression levels of pro-inflammatory markers in BV2 cells. Murine BV2 cells were serum starved for $24 \mathrm{~h}$ prior to treatment with $0.1 \mu \mathrm{g} / \mathrm{ml}$, $1.0 \mu \mathrm{g} / \mathrm{ml}$ and $10 \mu \mathrm{g} / \mathrm{ml}$ of LPS for $24 \mathrm{~h}$, shown with no LPS controls. RNA was extracted by TRISURE reagent and reverse transcribed into cDNA. The mRNA levels of (A) IL-1 $\beta,(\mathbf{B}) I L-6,(\mathbf{C})$ IL-10, (D) Itgam, (E) AIF1, (F) Adgre1, (G) CD68 and (H) NOS2 were determined by real time qPCR, using S18 as an internal housekeeping gene. Levels were quantified using the Delta-CT method. Data represents means of 4 - 6 samples for each group. Results are 
expressed as mean \pm SEM. ${ }^{*} \mathrm{p}<0.05,{ }^{* *} \mathrm{p}<0.01,{ }^{* * *} \mathrm{p}<0.001$ vs control as determined by one-way ANOVA followed by Dunnett's post-hoc test. (Gene: protein acronyms): $I L-1 \beta$ : Interleukin 1 $\beta, I L-6$ : Interleukin 6, IL-10: Interleukin 10, Itgam: CD11b, AIF1: Iba1, Adgre1: F4/80, CD68: Cluster of differentiation 68 (CD68), NOS2: inducible nitric oxide synthase (iNOS), $S 18$ : ribosomal protein $S 18$.

2.2 Time-course analyses showing temporal gene expression changes of pro-inflammatory cytokines and microglial activation markers in LPS-treated BV2 cells

Once established that $1 \mu \mathrm{g} / \mathrm{ml}$ LPS was the most effective concentration to trigger inflammation in our cell model, we sought to determine the temporal response of BV2 cells to treatment. We conducted a time-course analysis of the gene expression profiles of the markers used in the main experiments (see Table 2$)$ at five different time points $(0,6,12$, 24 and $48 \mathrm{~h})$. We found that, after $6 \mathrm{~h}$ exposure to LPS, there were significant increases in $I L-1 \beta\left(\mathrm{F}(4,25)=196,{ }^{* * *} \mathrm{p}<0.001\right), I L-6\left(\mathrm{~F}(4,24)=16.87,{ }^{* * *} \mathrm{p}<0.001\right), \operatorname{CD} 68(\mathrm{~F}(4,23)=16.99$, $\left.{ }^{* * *} \mathrm{p}<0.001\right)$ and NOS2 transcripts $\left(\mathrm{F}(4,19)=262.6,{ }^{* *} \mathrm{p}<0.001\right)($ Fig. 2a-b, 2 g and 2h). However, IL-10, Itgam, AIF1 and Adgre1 expression levels did not show significant changes (Fig. 2c-f), ( $\mathrm{p}>0.05$ vs. control).

After $12 \mathrm{~h}$ of LPS exposure, the majority of the pro-inflammatory markers showed significant increases. These included: $I L-1 \beta\left({ }^{* * *} \mathrm{p}<0.001\right), I L-6\left({ }^{* * *} \mathrm{p}<0.001\right), I L-10(\mathrm{~F}(4,19)=$ 7.316, $\left.{ }^{* * *} \mathrm{p}<0.001\right)$, Adgre1 $\left(\mathrm{F}(4,25)=27.15,{ }^{* * *} \mathrm{p}<0.001\right), \operatorname{AIF1}\left(\mathrm{F}(4,25)=8.547,{ }^{*} \mathrm{p}<0.05\right)$, CD68 $\left({ }^{* * *} \mathrm{p}<0.001\right)$ and NOS2 $\left.{ }^{* * *} \mathrm{p}<0.001\right)$ (Fig. 2a-c and 2e-h).

BV2 cells exposed to LPS for $24 \mathrm{~h}$ resulted in significant increases in $I L-1 \beta\left({ }^{* * *} \mathrm{p}<0.001\right)$, IL-6 ( $\left.{ }^{* *} \mathrm{p}<0.01\right)$, Adgre1 ( $\left.{ }^{* * *} \mathrm{p}<0.001\right), C D 68\left({ }^{* *} \mathrm{p}<0.01\right)$ and NOS2 $\left({ }^{* *} \mathrm{p}<0.001\right)$ when compared with control (Fig. 2a-b, 2f-h). 
After 48h of LPS exposure, $I L-1 \beta\left({ }^{* * *} \mathrm{p}<0.001\right), I L-6\left({ }^{* *} \mathrm{p}<0.001\right), A I F 1\left({ }^{* * *} \mathrm{p}<0.001\right), A d-$ gre1 $\left({ }^{* * *} \mathrm{p}<0.001\right)$, and NOS2 genes $\left({ }^{* *} \mathrm{p}<0.001\right)$ were all significantly upregulated (Fig. 2a$\mathbf{b}, \mathbf{2 e}$ and $\mathbf{2 h}$ ). IL-10, Itgam and CD68 mRNA levels did not differ from controls at this time point ( $\mathrm{p}>0.05)$ (Fig. 2c-d and 2g).

A

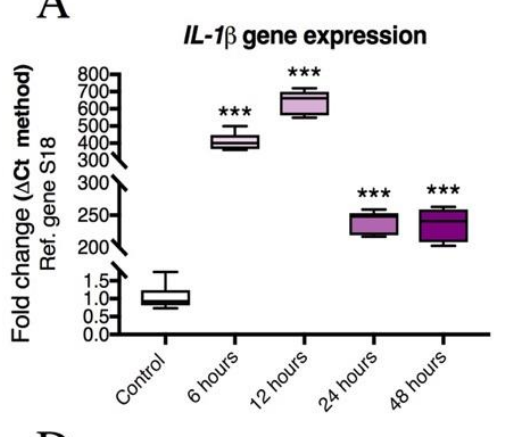

$\mathrm{D}$

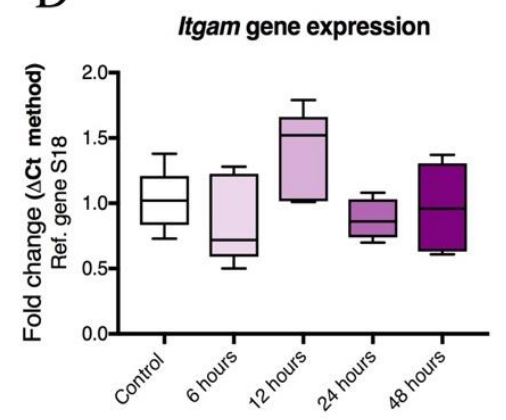

$\mathrm{G}$

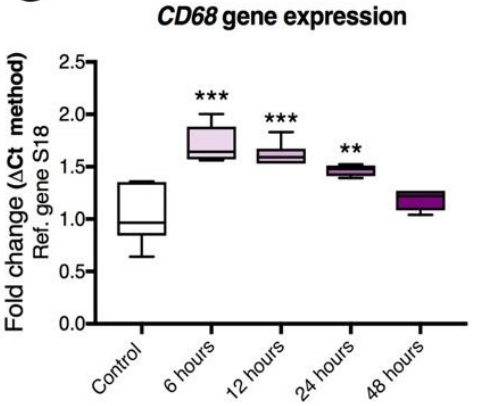

B

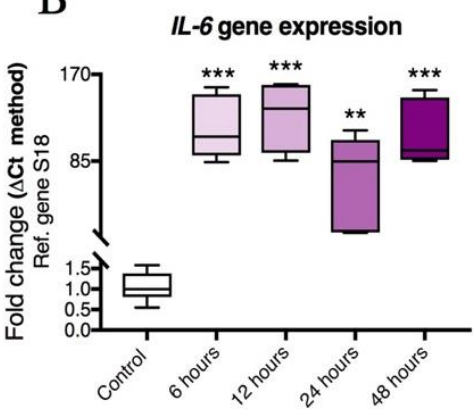

$\mathrm{E}$

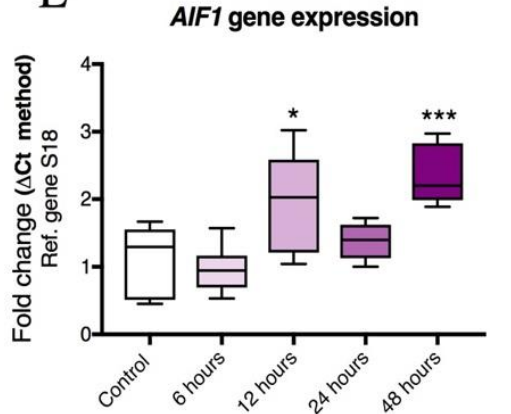

$\mathrm{H}$
$\mathrm{C}$

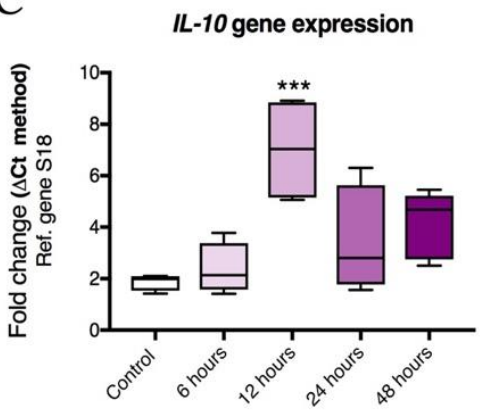

$\mathrm{F}$

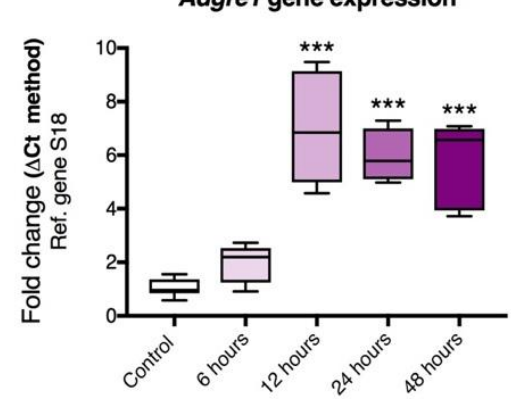

Figure 2. Time-course analyses of the mRNA expression levels of pro-inflammatory markers and cytokines after exposure to LPS. Murine BV2 cells were serum starved for $24 \mathrm{~h}$ prior to treatment with $1.0 \mu \mathrm{g} / \mathrm{ml}$ of LPS for 0, 6, 12, 24 and $48 \mathrm{~h}$. The RNA was extracted by TRISURE reagent and reverse transcribed into cDNA. The mRNA levels of (A) IL-1 $\beta$, (B) IL-6, (C) IL-10, (D) Itgam, (E) AIF1, (F) Adgre1, (G) CD68 and (H) NOS2 were determined by RT-qPCR with S18 as an internal housekeeping gene. Levels were quantified by DCT method. Data represents means of $4-6$ samples for each group. Results are expressed as mean \pm SEM. ${ }^{*} \mathrm{p}<0.05,{ }^{* *} \mathrm{p}<0.01,{ }^{* * *} \mathrm{p}<0.001$ vs control as determined by one-way ANOVA followed by Dunnett's post-hoc test. (Gene: protein acronyms): IL-1 $\beta$ : Interleukin 1 $\beta, I L-6$ : Interleukin 6, IL-10: Interleukin 10, Itgam: CD11b, AIF1: Iba1, Adgre1: F4/80, CD68: Cluster of differentiation 68 (CD68), NOS2: iNOS, S18: ribosomal protein S18.

\subsection{LPS treatment alters PACAP, VIP and receptor transcripts in BV2 cells exposed to LPS}

In order to evaluate whether LPS perturbs mRNA expression levels of PACAP, VIP and/or their receptors, BV2 cells treated with LPS at $1 \mu \mathrm{g} / \mathrm{ml}$ for $24 \mathrm{~h}$-and controls- were supplemented with either 100nM PACAP, or 100nM VIP [30,31,51-53]. In the absence of LPS, stimulation with PACAP $(100 \mathrm{nM})$ or VIP $(100 \mathrm{nM})$ significantly increased PACAP gene (Adcyap1) mRNA expression by either 6- or 8 -fold $\left(\left(\mathrm{F}(5,29)=57.91,{ }^{* * *} \mathrm{p}<0.001\right)\right.$ (Fig. $3 a)$, but did not reliably increase the expression of the genes for Vip, PAC1 receptor (Adcyap1r1), VPAC1 receptor (Vipr1) or VPAC2 receptor (Vipr2) (p>0.05, Fig. 3b-e). LPS administration did not affect any of the genes encoding PACAP, VIP or their related re- 
ceptors (Fig. 3a-e); however, co-treatment of LPS-treated cells with PACAP or VIP resulted in a global and significant increase in transcript levels of both the peptides and their receptors (\#\# $<0.001$ Vs LPS, Fig. 3a-e).
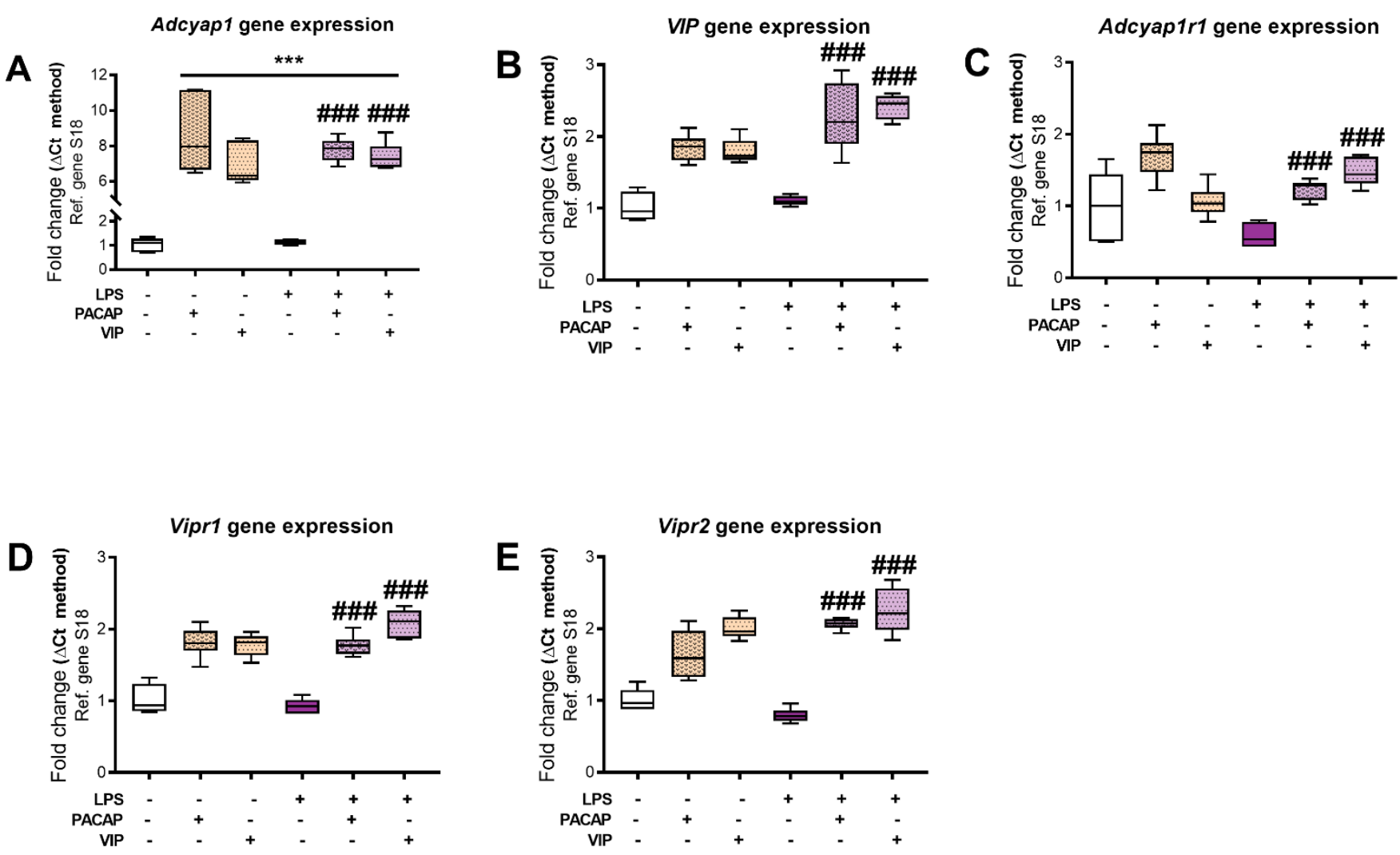

Figure 3. PACAP, VIP and receptors gene expression after treatment with LPS in the presence or not of exogenous PACAP or VIP. Real time qPCR analyses of (A) Adcyap1, (B) Vip, (C) Adcyap1r1, (D) Vipr1 and (E) Vipr2 mRNA levels in BV2 cells that were either left untreated, treated with 100nM PACAP, 100nM VIP, $1 \mu \mathrm{g} / \mathrm{ml}$ LPS alone or in the presence of PACAP or VIP after 24h. Relative changes in mRNA levels were determined using the DCT method and normalized to the ribosomal protein subunit S18, here used as the housekeeping gene. Data represent the mean of 3 - 6 biological replicates for each group. Results are expressed as mean \pm SEM. ${ }^{* *} \mathrm{p}<0.001$ vs control, \#\# $\mathrm{p}<0.001$ vs LPS only as determined by one-way ANOVA followed by Tukey post-hoc test. (Gene: protein acronyms): Adcyap1: PACAP, Vip: VIP, Adcyap1r1: PAC1 receptor, Vipr1: VPAC1 receptor, Vipr2: VPAC2 receptor, S18: ribosomal protein S18.

\subsection{PACAP or VIP treatment rescue LPS-induced AIF1/Iba1 and NOS2/iNOS levels in BV2 microglial cells}

To assess if PACAP and VIP exerted anti-inflammatory effects in BV2 cells, we exposed cell cultures to LPS and measured gene and protein expression of the microglial activation marker AIF1/Iba1 (Fig. 4a-e). In addition, since production of NO is of particular importance in the pathophysiology of several CNS disorders and due to the toxicity of its by-products, e.g. peroxynitrates, and because of its known role as an inflammatory mediator [54-56], we also assessed the expression levels of NOS2/iNOS. We examined the effects of PACAP and VIP in both the presence and absence of LPS stimulation. Our results show that the LPS challenge caused a significant increase of both $\operatorname{AIF1}(\mathrm{F}(5,30)=$ $24.89,{ }^{* * *} \mathrm{p}<0.001$ Vs control, Fig. 4c) and NOS2 mRNA levels $\left(\mathrm{F}(5,26)=240.8,{ }^{* * *} \mathrm{p}<0.001\right.$, Fig. 4e), accompanied by similar increases in protein expression (Iba1: F $(5,18)=6.352$, ${ }^{* *} \mathrm{p}<0.01$ and iNOS: F $(5,18)=5.666,{ }^{* *} \mathrm{p}<0.01$, Fig. 4a-b and 4d). Treatment with either PACAP or VIP inhibited the LPS-induction of both AIF1 (\#\# $<0.01$ and \#\#\# $<0.001$ Vs LPS, respectively) and NOS2 gene expression (\#\# $\mathrm{p}<0.001$ Vs LPS for both peptides), as well as the expression of the translated Iba1 (\#p $<0.05$ or \#\#p $<0.01$ Vs LPS, respectively) and iNOS proteins (\#p<0.05 Vs LPS for both peptides) (Fig. 4a, $\mathbf{4 b}$ and $\mathbf{4 d}$ ). 
To complement our biochemical analyses, we performed immunocytochemistry. BV2 microglia were grown on coverslips under each of the experimental conditions (untreated control, LPS, LPS+PACAP and LPS+VIP) and stained using an antibody to Iba1 (Fig. 4f). Iba1 expression was increased in LPS-only treated cells $\left(F(3,20)=28.59,{ }^{* *} p<0.01\right.$ Vs Ctrl, Fig. 4f-g). After application of either PACAP or VIP, the intensity of the staining was a significantly decreased when compared to the LPS group (\#\#\#p<0.001 for both PACAP and VIP, Fig. 4f-g).

A
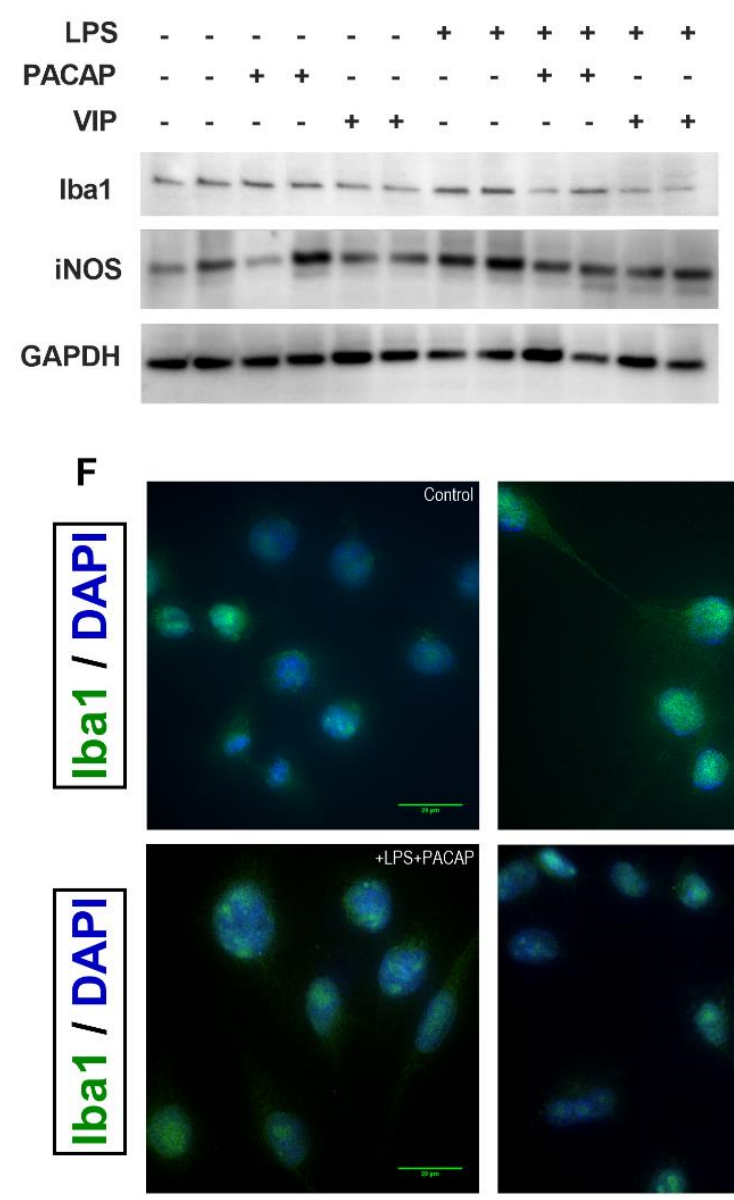

B

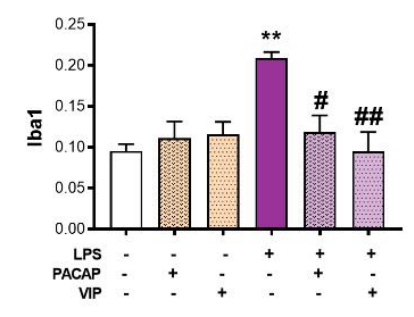

D

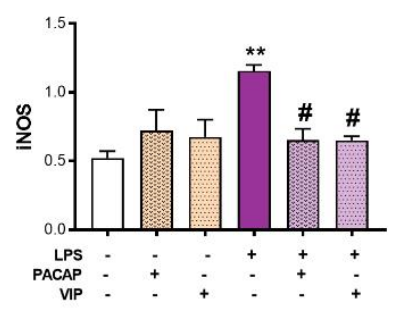

C AlF1 gene expression

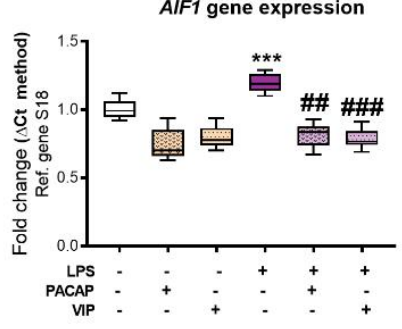

E NOS2 gene expression

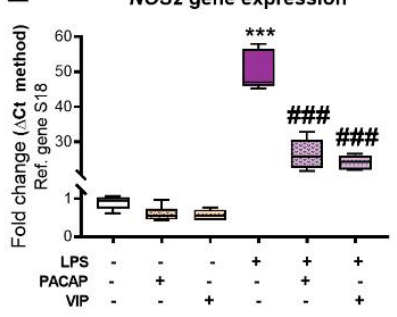

\section{G}

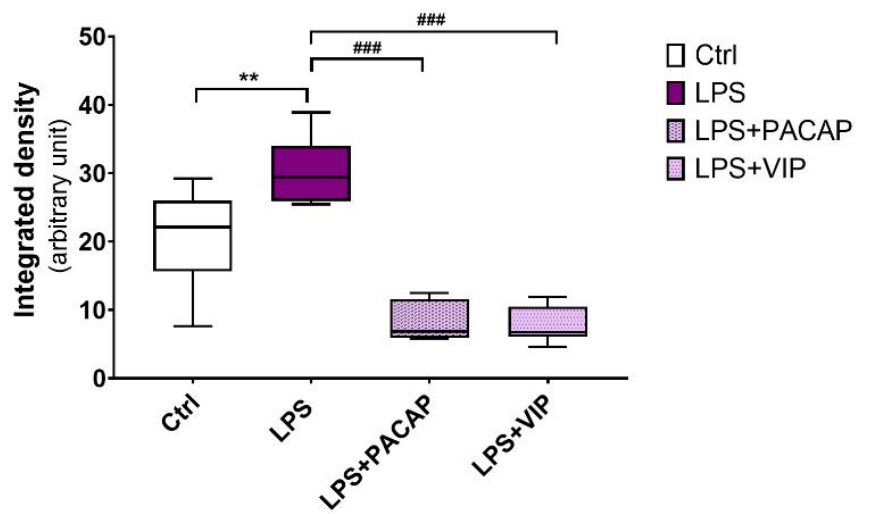

Figure 4. Effects of treatment with PACAP or VIP on LPS-induced microglia activation markers in BV2 cells. Real time qPCR and Western blot analyses depicting AIF1/Iba1 and NOS2/iNOS mRNA and protein expression levels in cells exposed to LPS $(1 \mu \mathrm{g} / \mathrm{ml})$ and after co-treatment with either PACAP or VIP at 24h. mRNA levels of AIF1 (B) and NOS2 (D) and related proteins (Iba1 [A] and iNOS [C]) are shown. qPCR data represents means of $\mathrm{n}=5-6$ biological replicates for each group. Results are expressed as mean \pm SEM. ${ }^{* *} \mathrm{p}<0.01$ or ${ }^{* * *} \mathrm{p}<0.001$ vs control; \#p $<0.05, \# \# \mathrm{p}<0.01$ or \#\#\#p<0.001 vs LPS only, as determined by one-way ANOVA followed by Tukey post-hoc test. Western blot data represents the mean of 4 independent experiments, each run in duplicate. Representative immunocytofluorescence photomicrographs (F) and bar graph showing semi-quantification of Iba1 fluorescent intensity $(\mathbf{G})$ in BV2 cells exposed to LPS $(1 \mu \mathrm{g} / \mathrm{ml})$ and co-treated with either PACAP or VIP for $24 \mathrm{~h}$. Nuclei were counterstained with DAPI. Results are expressed as mean \pm SEM. ${ }^{*}$ p $<0.05$ vs. control, \#\# $\mathrm{p}<0.0001$ vs. LPS-treated cells, as determined by one-way ANOVA followed by Sidak's post-hoc test. At least six images were taken from each treatment group from 2 separate experiments where 1 representative image is shown. Magnification $=63.5 \times$. Scale bar $=20 \mu \mathrm{m}$. AIF1: Ionized calcium binding adaptor molecule 1 (Iba1), GAPDH: Glyceraldehyde3-phosphate deyhydrogenase, S18: ribosomal protein subunit. 
2.5 PACAP or VIP treatment reduce the expression of pro-inflammatory cytokines in BV2 cells exposed to LPS

In these experiments, we evaluated whether PACAP or VIP reduced the heightened levels of pro-inflammatory cytokines in BV2 microglial cells following exposure to LPS. Cells were exposed to LPS and treated as described above. Additional drug-treatment controls were also included. As shown in Fig. 5a-f, LPS treatment strongly increased the mRNA expression of IL-1 $\beta$ (F5, 30=1411, $\left.{ }^{* *} \mathrm{p}<0.001\right)$, IL-6 (F5, 30=1893, $\left.{ }^{* * *} \mathrm{p}<0.001\right)$, Itgam (F5, 30=66.69, $\left.{ }^{* * *} \mathrm{p}<0.001\right)$, Adgre1 (F5, 30=443, $\left.{ }^{* *} \mathrm{p}<0.001\right)$ and CD68 (F5, 30=61.94, $\left.{ }^{* * *} \mathrm{p}<0.001\right)$ compared to untreated groups. Of note, the mRNA expression levels of the anti-inflammatory cytokine IL-10 remained unchanged (Fig. 5c, p>0.05).

PACAP treatment of cells exposed to LPS significantly decreased the mRNA expression levels of IL-1 $\beta$ (\#\#\#<0.001), IL-6 (\#\# $<<0.001)$, Itgam (\#\#p<0.001), Adgre1 (\#p<0.05) and CD68 (\#\#\#<00.001) when compared with the LPS only group (Fig. 5a, 5b, 5d-f). PACAP treatment did not affect IL-10 mRNA expression levels (Fig. 5c, p>0.05).

VIP treatment of cells exposed to LPS produced similar patterns of change to those seen following PACAP treatment. Specifically, there were significant reductions in IL-1 $\beta$ $(\# \#$ p $<0.001)$, IL-6 (\#\#\#< $<0.001)$, Itgam (\#\#p<0.001) and CD68 mRNAs (\#\#p<0.001) (Fig. 5a, 5b, 5d and 5f). Once again, VIP did not affect IL-10 gene expression (Fig. 5c, p>0.05). Adgre1 transcript levels were also reduced, although this decrease was not statistically significant (Fig. 5f, p>0.05).
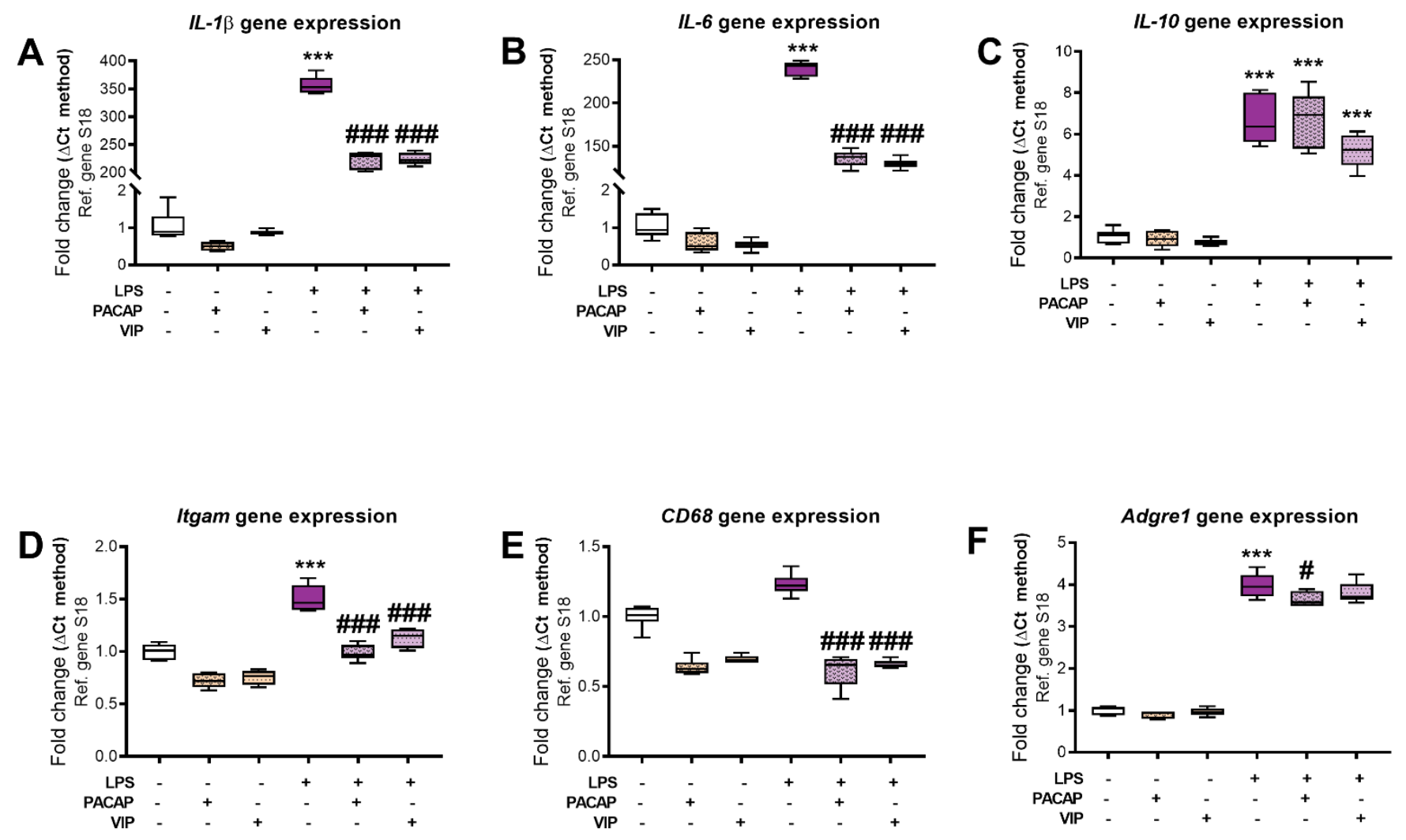

Figure 5. Transcript levels of inflammatory markers after treatment of BV2 cells with LPS alone, or in combination with PACAP or VIP. Murine BV2 cells exposed or not to LPS $(1 \mu \mathrm{g} / \mathrm{ml})$ for $24 \mathrm{~h}$ were co-treated with either PACAP or VIP and mRNA levels were assessed by real time qPCR. Expression of $I L-1 \beta$ (A), IL-6 (B), IL-10 (C), Itgam (D), Adgre1 (E) and CD68 (F) are shown. Transcript levels were calculated using the Delta-CT method. Data represents the means of 5 - 6 samples for each group. Results are expressed as mean \pm SEM. ${ }^{* * *} \mathrm{p}<0.001$ vs control, \# $\mathrm{p}<0.05$ and \#\#\# $\mathrm{p}<0.001$ vs LPS only, as determined by one-way ANOVA followed by Tukey post-hoc test. $I L-1 \beta$ : Interleukin 1-beta, IL-6: Interleukin 6, IL-10: Interleukin 10, Itgam: CD11b, Adgre1: F4/80, CD68: Cluster of differentiation 68, S18: ribosomal protein subunit S18. 


\subsection{PACAP or VIP treatment reduce the release of nitrites in the culture media}

To determine whether the downregulation of NOS2/iNOS induced by PACAP- or VIP was paralleled by reductions in the level of nitrites secreted by the cells, the relative abundance of NO was measured in the culture media using the Griess method [57]. As shown in Figure 6, the LPS-treated group showed a substantial and significant increase in nitrite levels when compared with control (F3, 44=201.4, $\left.{ }^{* * *} \mathrm{p}<0.001\right)$ (Fig. 6). Treatment with PACAP or VIP significantly reduced LPS-evoked NO release $(\# \# \# p<0.001$ for PACAP and VIP, respectively), although it did not return to control levels ( ${ }^{* * *} \mathrm{p}<0.001$ for PACAP and VIP, respectively).

\section{Nitrite levels}
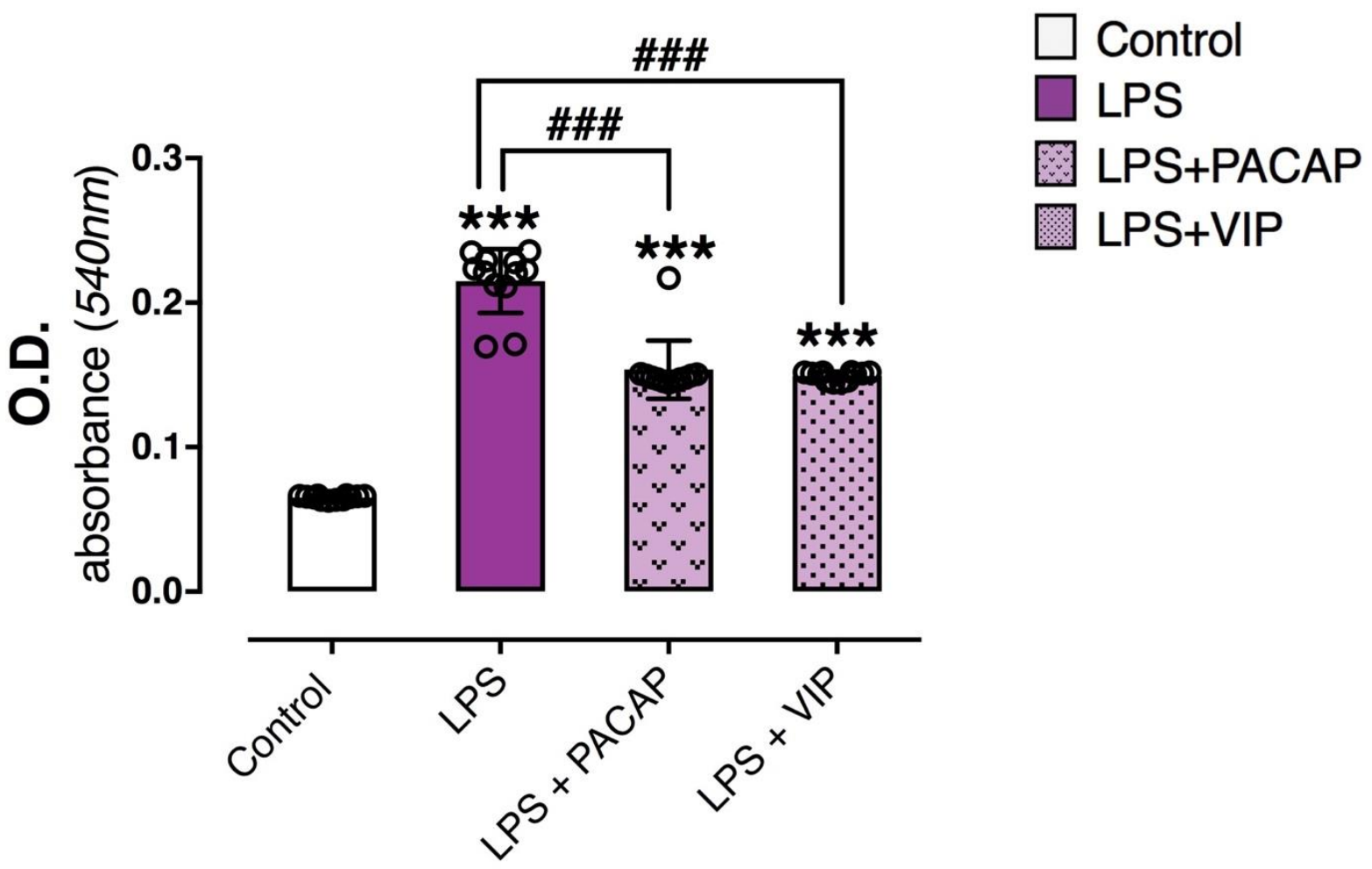

Figure 6. Release of nitrates in BV2 cells exposed to LPS and following treatment with PACAP or VIP. BV2 cells plated at $5 \times 10^{5}$ in $25 \mathrm{~cm}^{2}$ flasks were starved with $1 \%$ full growth media (FGM) for $24 \mathrm{~h}$ prior to treatment with $10 \%$ FGM (Control), $1.0 \mu \mathrm{g} / \mathrm{ml}$ LPS, $1.0 \mu \mathrm{g} / \mathrm{ml}$ LPS + 100nM PACAP and 1.0 $\mathrm{g} / \mathrm{ml}$ LPS + 100nM VIP for 24h. Media was then replaced with treatment-free media and allowed a further $24 \mathrm{~h}$ incubation to allow NO accumulation. The culture media was then aspirated and subjected to Griess reaction to obtain the readings using an ELISA reader (540nm filter). This experiment was repeated with at least two independent batches of BV2 cells in two separate experiments. Results are expressed as mean \pm SEM. ${ }^{* * *} \mathrm{p}<0.001$ vs. control, \#\# $\mathrm{p}<0.001$ vs. LPS-treated cells, as determined by one-way ANOVA followed by Tukey post-hoc test. O.D: Optical density.

\subsection{Distinct effects of PACAP or VIP treatment on LPS-stimulated BV2 cell morphology.}

When BV2 cells were challenged with LPS and co-treated with either PACAP or VIP, we observed gross morphological differences in the cells between the two treatments. To systematically describe these differences, we conducted morphometric analyses of untreated cells, or cells exposed for $24 \mathrm{~h}$ to either LPS, or LPS in combination with PACAP or VIP.

Measurements of cell surface areas in the BV2 microglial cell lineage revealed a broad heterogeneity among cells, with soma surface areas ranging from very small to very large $\left(\min\right.$ size $=7 \mu \mathrm{m}^{2}-$ max size $\left.=924 \mu \mathrm{m}^{2}\right)$. This large heterogeneity of cell sizes across treatment groups prompted us to conduct a distribution analysis aimed at determining if each 
treatment resulted in a distinct pattern of distribution of cells as a function of their size. As shown in Fig. 7a-b, ranking of cells based on surface area revealed three distinct cell subgroups; (i) small cells $=<200 \mu \mathrm{m}^{2}$; (ii) mid-sized cells $=200-400 \mu \mathrm{m}^{2}$ and; (iii) large cells= $>400 \mu \mathrm{m}^{2}$ ) whose patterns of changes were distinctly affected across our treatment groups. We detected a strong correlation between cell surface area and the length of cellular processes (Pearson $\mathrm{r}=0.953,{ }^{* * * *} \mathrm{p}<0.0001$, Fig. 8a) which was maintained across each of the three cell-size categories identified ( $\mathrm{r}=0.872$ for small cells, $\mathrm{r}=0.726$ for mid-sized cells and $\mathrm{r}=0.726,{ }^{* * *} \mathrm{p}<0.001$, respectively, Fig. $\left.8 \mathbf{b}-\mathbf{d}\right)$. On the basis of this analysis, we used these features to classify BV2 cell sizes in subsequent morphological experiments.

In cells exposed to LPS, the number and percentage of cells presenting with a large soma was strongly increased when compared with untreated controls (249/440 [56.69\%] Vs 20/440 [4.55\%] in controls, Fig. $7 \mathbf{c}$ and d). As predicted, these results were associated with a drastic reduction in the number of small-sized cells (53/440 [12.05\%] Vs 273/440 [62.05\%] in controls), but no changes in the number of mid-sized cells (138/440 [31.36\%] Vs 147/440 [33.34\%], Fig. 7c and d).

When LPS-exposed BV2 cells were co-treated with PACAP, we observed a major shift towards a phenotype characterized by small BV2 cells (238/440 [54.09\%] Vs 53/440 [12.05\%], Fig. 7a and $\mathbf{b})$, and a robust reduction in the number of large-sized cells (70/440 [15.91\%] Vs 249/440 [56.69\%] was observed in LPS-treated cells, Fig. 7d and e). Similar to untreated or LPS-treated cells, PACAP treatment did not affect the number of mid-sized cells $(132 / 440$ [30.00\%] Vs 147/440 [33.34\%].

BV2 cells that were exposed to LPS and co-treated with VIP showed a distinct redistribution of cells, based on their cell surface areas (Fig. $7 \mathbf{a}$ and $\mathbf{b})$. In contrast to PACAPtreated cells, VIP treatment triggered only a partial shift towards small-sized cells (124/440 [28.18\%] Vs 238/440 [54.09\%] in PACAP-treated cells, Fig. 7d and f). In contrast, we observed a predominant shift towards mid-sized cells (213/440 [48.41\%], Fig. 7f), an effect not seen in any of the other treatment groups (138/440 [31.36\%] in controls, 147/440 [33.34\%] in LPS-treated cells and 132/440 [30.00\%] in PACAP-treated cells, respectively, Fig. 7c-f). 

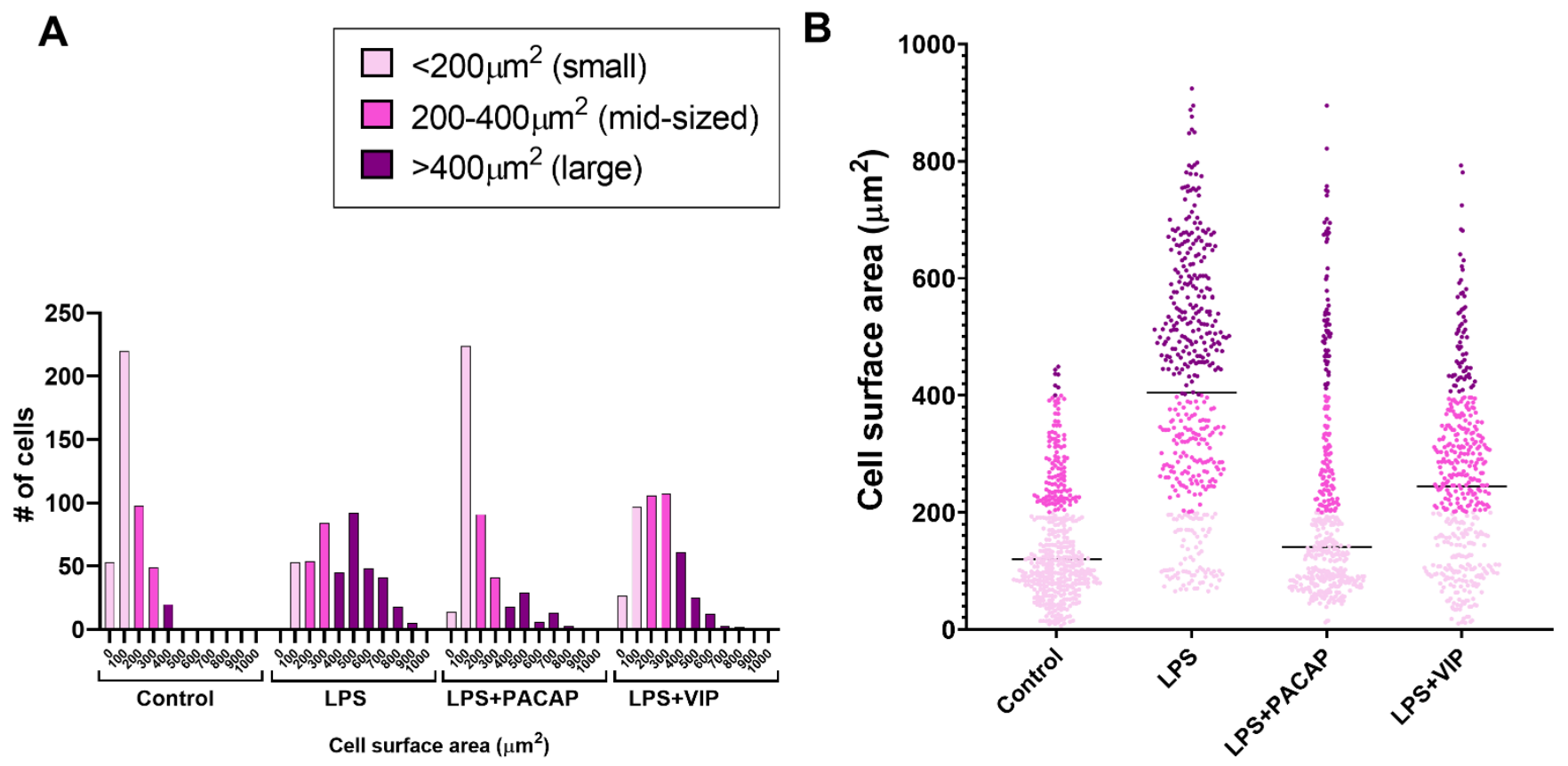

$\mathbf{E}$

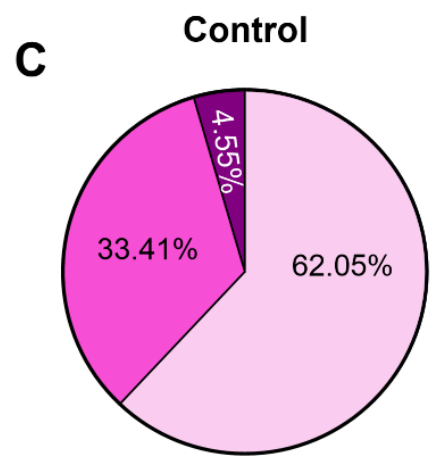

D

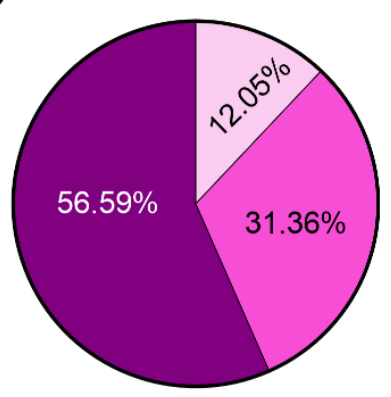

LPS+PACAP

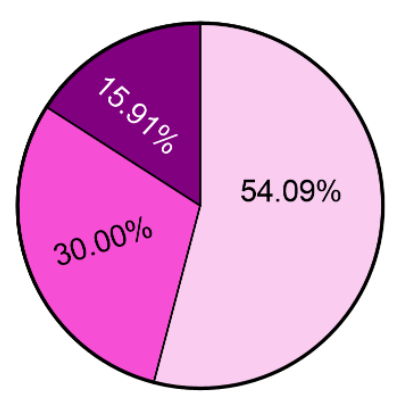

LPS+VIP

F

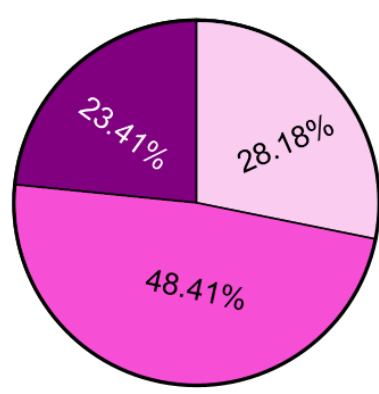

Figure 7. Redistribution of BV2 cell subpopulations based on cell surface area after treatment with LPS or in combination with PACAP or VIP. BV2 cells plated at $5 \times 10^{5}$ in $25 \mathrm{~cm}^{2}$ flasks were starved with $1 \%$ FGM for $24 \mathrm{~h}$ prior to treat-

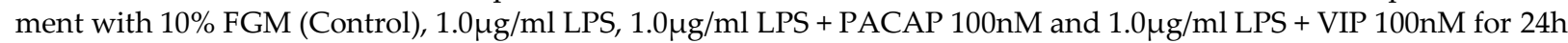
then images were captured using Nikon Eclipse Ts2 inverted microscope. Images were assigned to investigators who were blind to experimental conditions and cells were classified as either small $\left(<200 \mu \mathrm{M}^{2}\right)$, mid-sized $\left(200-400 \mu \mathrm{M}^{2}\right)$, or large $\left(>400 \mu \mathrm{M}^{2}\right)$ (Please refer to Table 1 for further details on cells characteristics). Analyses were performed using Image J 1.51 (NIH) software. Measurements of cell surface area were performed on a total of 1760 cells (440 cells $\times$ treatment group). (A) Distribution of cell populations based on cell surface area identify distinct patterns across treatments. (B) Scatter plot of cell surface area distribution in each treatment group (the black line depicts the median). (C-F) Pie charts showing the percentage of distribution of cell populations after ranking into small, mid-sized or large cells. 


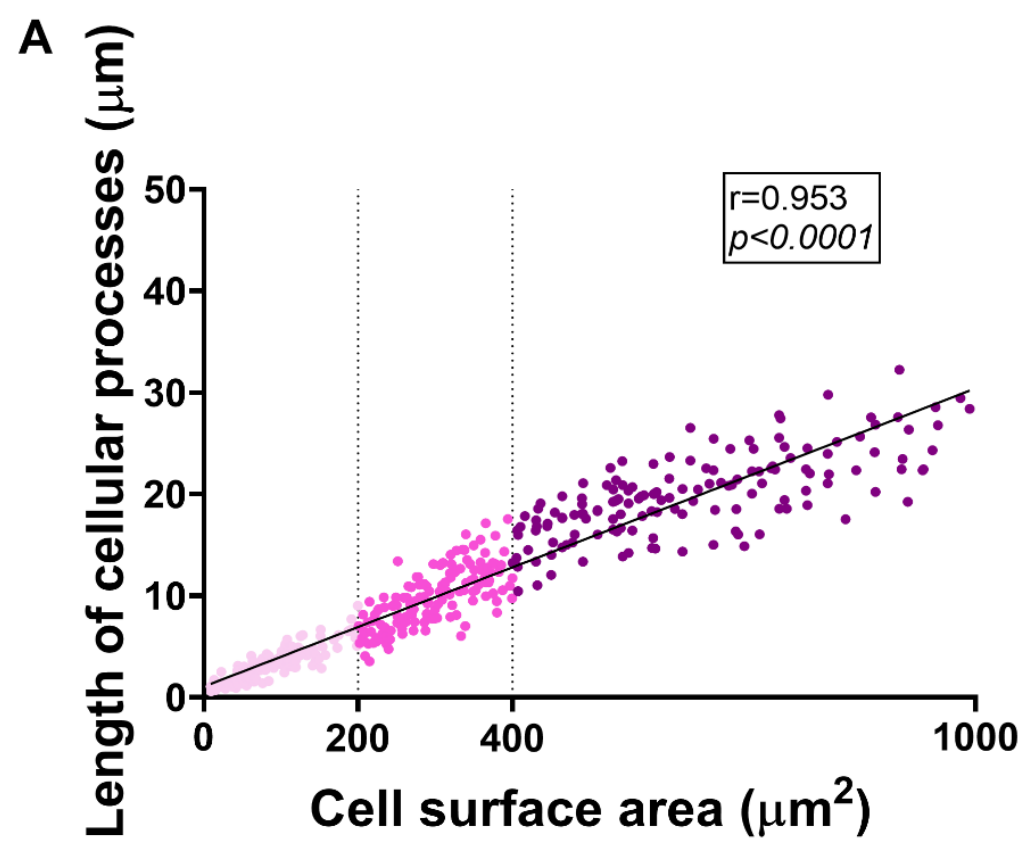

B

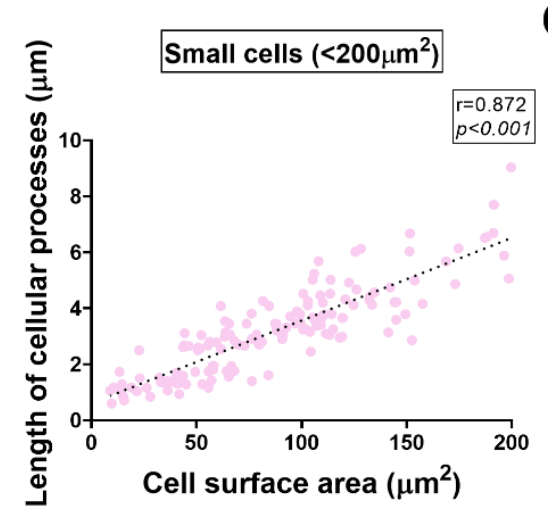

C

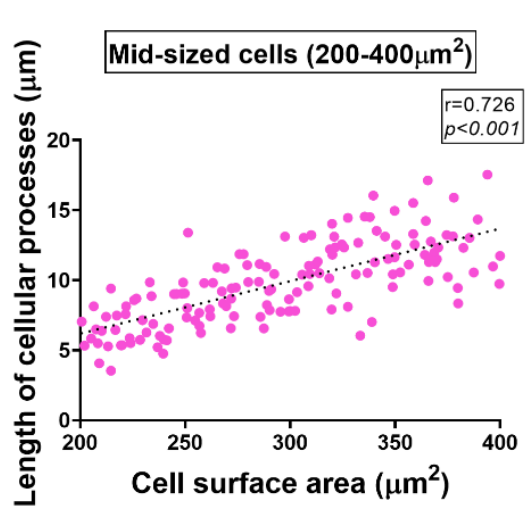

D

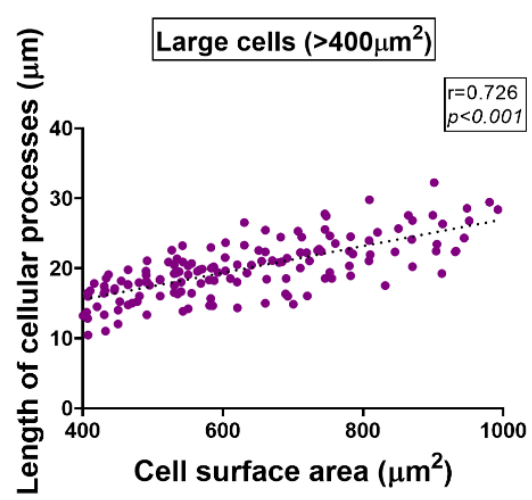

Figure 8. Correlation between cell surface area and length of cellular processes. BV2 cells plated at $5 \times 10^{5}$ in $25 \mathrm{~cm}^{2} \mathrm{flasks}$ were starved with 1\% FGM for $24 \mathrm{~h}$ prior to treatment with 10\% FGM (Control), $1.0 \mu \mathrm{g} / \mathrm{ml} \mathrm{LPS}, 1.0 \mu \mathrm{g} / \mathrm{ml}$ LPS + PACAP $100 \mathrm{nM}$ and $1.0 \mu \mathrm{g} / \mathrm{ml}$ LPS + VIP 100nM for $24 \mathrm{~h}$ then images were captured using Nikon Eclipse Ts2 inverted microscope. Images were assigned to investigators who were blind to experimental conditions. Measurements of cellular processes were performed using Image J 1.51 (NIH) software. The average length of cellular processes (expressed in $\mu \mathrm{m}$ ) was obtained by averaging the measurements of 2-3 processes $\times$ cell. (A) Correlation between cell surface area and the length of cellular processes. Regression analyses showing significant correlations between cell surface area and length of cellular processes both in (B) Small cells $\left[<200 \mu \mathrm{m}^{2}\right],\left(\right.$ C) Mid-sized cells [200-400 $\mathrm{m}^{2}$ ] and (D) Large cells [ $\left.>400 \mu \mathrm{m}^{2}\right]$.

\subsection{VIP but not PACAP treatment causes the phenotypic shift of BV2 cells towards mid-sized spindle/bipolar-shaped cells after LPS challenge}

Once we had established that PACAP and VIP each differed in their abilities to segregate cell subpopulations within a distinct cell size-based category, we sought to determine whether changes in cell size might also relate to changes in cell morphology. Therefore, stereological analyses were undertaken in BV2 cells, treated as indicated above. In physiological conditions, BV2 cells exhibit three distinct morphologies: rounded, bipolar/spindle and multipolar shapes.

In comparing cell subpopulations, two-way RM ANOVA and Tukey post-hoc test, revealed ligand-selective effects of VIP and PACAP treatment $\times$ cell morphology interaction $(* * \mathrm{p}<0.01)$. Specifically, within the LPS+VIP group, we found that cells exhibiting a bipolar/spindle shape were the most frequently represented cell population (53\%), both in comparison with control groups $\left(23 \%,{ }^{* * *} \mathrm{p}<0.001 \mathrm{Vs}\right.$ Control) or LPS treated cells $(33 \%$, $\# \mathrm{p}<0.05$ Vs LPS) (Fig. 9a). 
None of the other cell morphologies (i.e. rounded or multipolar) were significantly different across treatment groups ( $p>0.05)$ (Fig. 9a).

In-depth analyses revealed that within each phenotype (i.e. rounded, spindle or multipolar cells), treatment with either LPS alone, or in combination with PACAP or VIP triggered a redistribution of the percentage of cells of a given size category (i.e. small, midsized and large cells). Specifically, we found that about $90 \%$ of all rounded BV2 cells were small sized $\left(>200 \mu \mathrm{m}^{2}\right)$, irrespective of treatment. Conversely, analyses of bipolar/spindleshaped cells showed that between $60-70 \%$ of these cells were mid-sized. However, in VIP stimulated cells this percentage increased to $80.19 \%$ (Fig. 9b), suggesting that VIP treatment not only affects the total population of bipolar-shaped cells, but also promotes their clustering into mid-sized cells in a unique manner.

Analyses of multipolar cells demonstrated that under the experimental conditions tested, this phenotype was not specifically associated with any cell size category with a varying percentage of $33-36 \%$ of multipolar cells falling either into small, mid-sized or large size category (Fig. 9b). The only exception was seen in the LPS group, where almost half of all the multipolar cells had a large soma (45.28\%), followed by $36.11 \%$ mid-sized and only $18.61 \%$ of small-sized cells. Additional morphological details are shown in Table 1. 
A

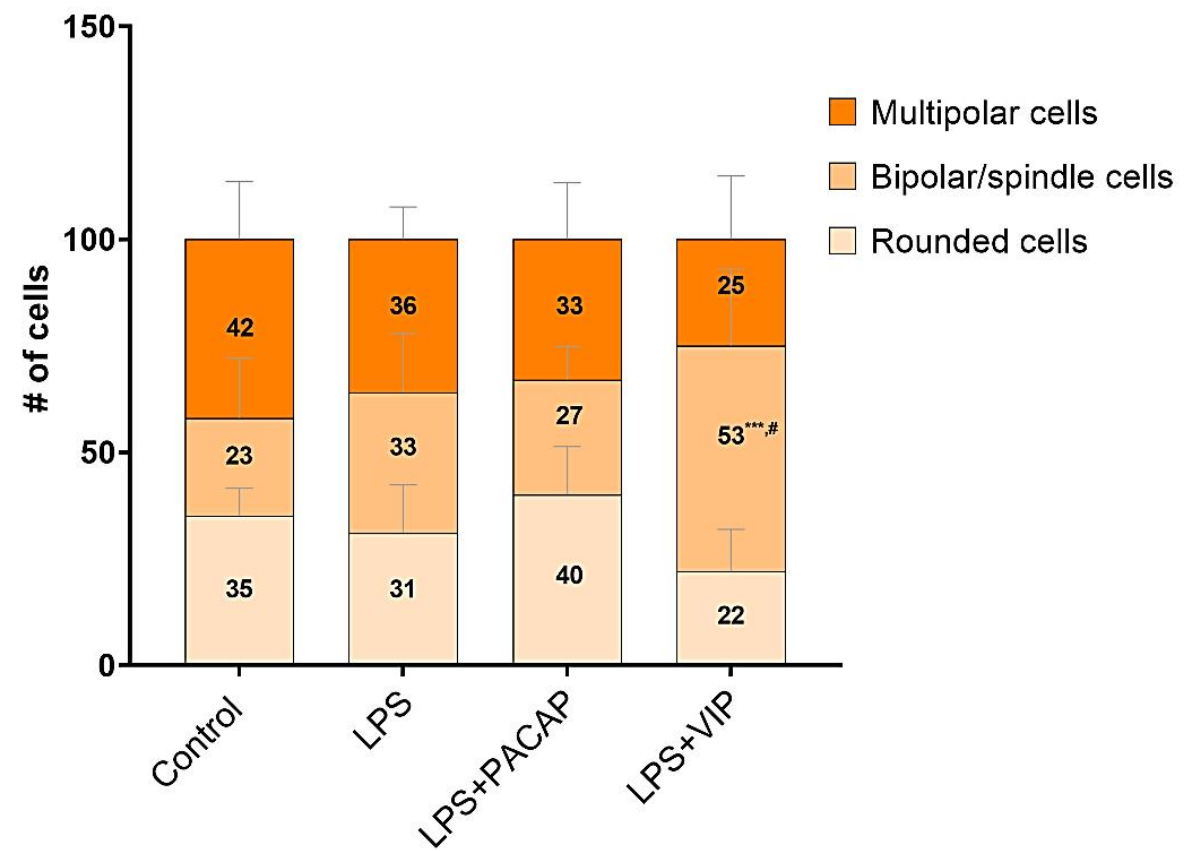

B

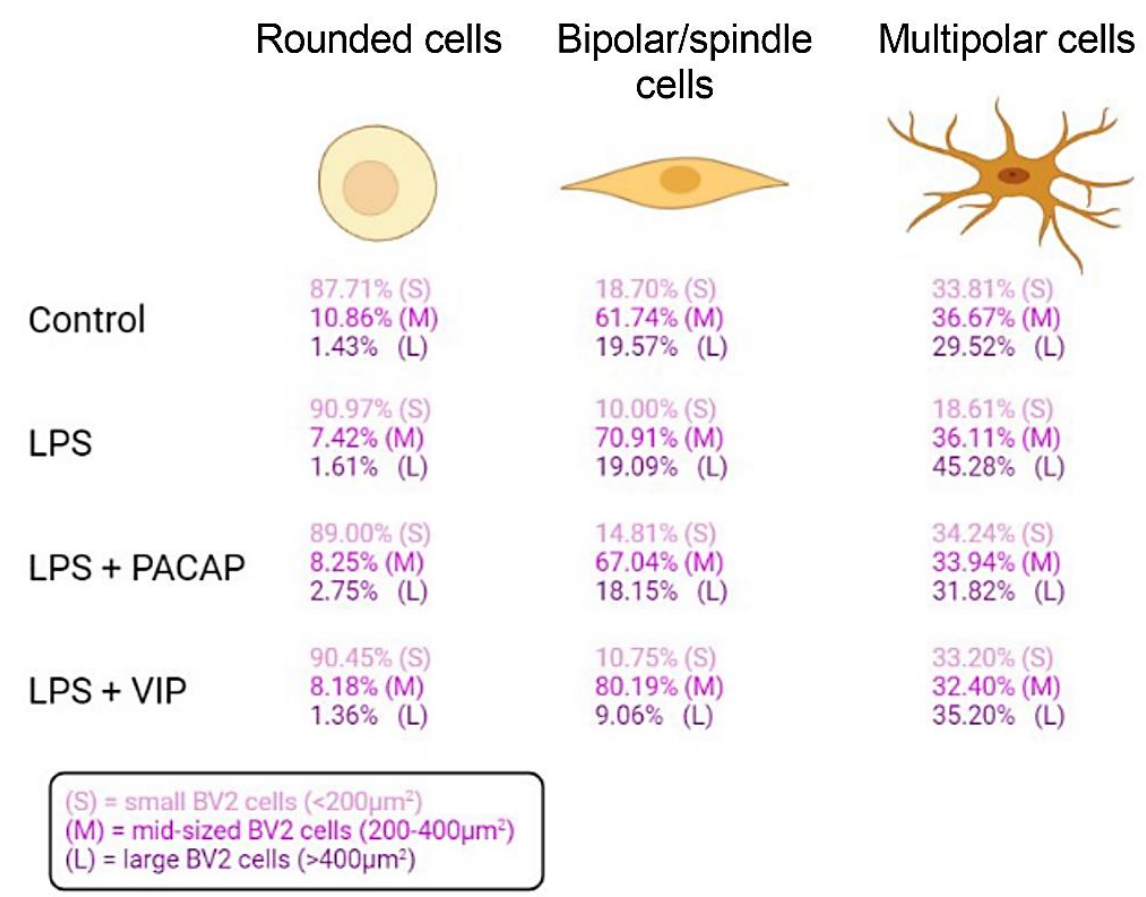

Figure 9. Redistribution of BV2 microglial cell subpopulations based on morphology after treatment with LPS only, LPS+PACAP and LPS+VIP. BV2 cells plated at $5 \times 10^{5}$ in $25 \mathrm{~cm}^{2}$ flasks were starved with $1 \%$ FGM for $24 \mathrm{~h}$ prior to treatment with 10\% FGM (Control), LPS $(1.0 \mu \mathrm{g} / \mathrm{ml})$, LPS + PACAP $(100 \mathrm{nM})$ and LPS + VIP $(100 \mathrm{nM})$ for 24h. Images were captured using Nikon Eclipse Ts2 inverted microscope. (A) Average number of cells presenting with either rounded-, bipolar/spindle- or multipolar-shape in each experimental condition. (B) Percentage of BV2 cells for each morphology that exhibited either a small (S), mid-sized (M) or large soma (L). Investigators conducting stereological and morphometric measurements were blind to the experimental conditions. Measurements and cell counts were performed using Image J 1.51 (NIH) software. An average of 100 cells per experimental condition were analysed, with each condition replicated using ten different batches of cells $(n=10) .{ }^{* *} \mathrm{p}<0.001 \mathrm{Vs}$ Control or $\# \mathrm{p}<0.05$ vs. LPS-treated cells, as determined by two-way RM ANOVA followed by Tukey post-hoc test. 
Table 1. Morphological features of BV2 microglial cells.

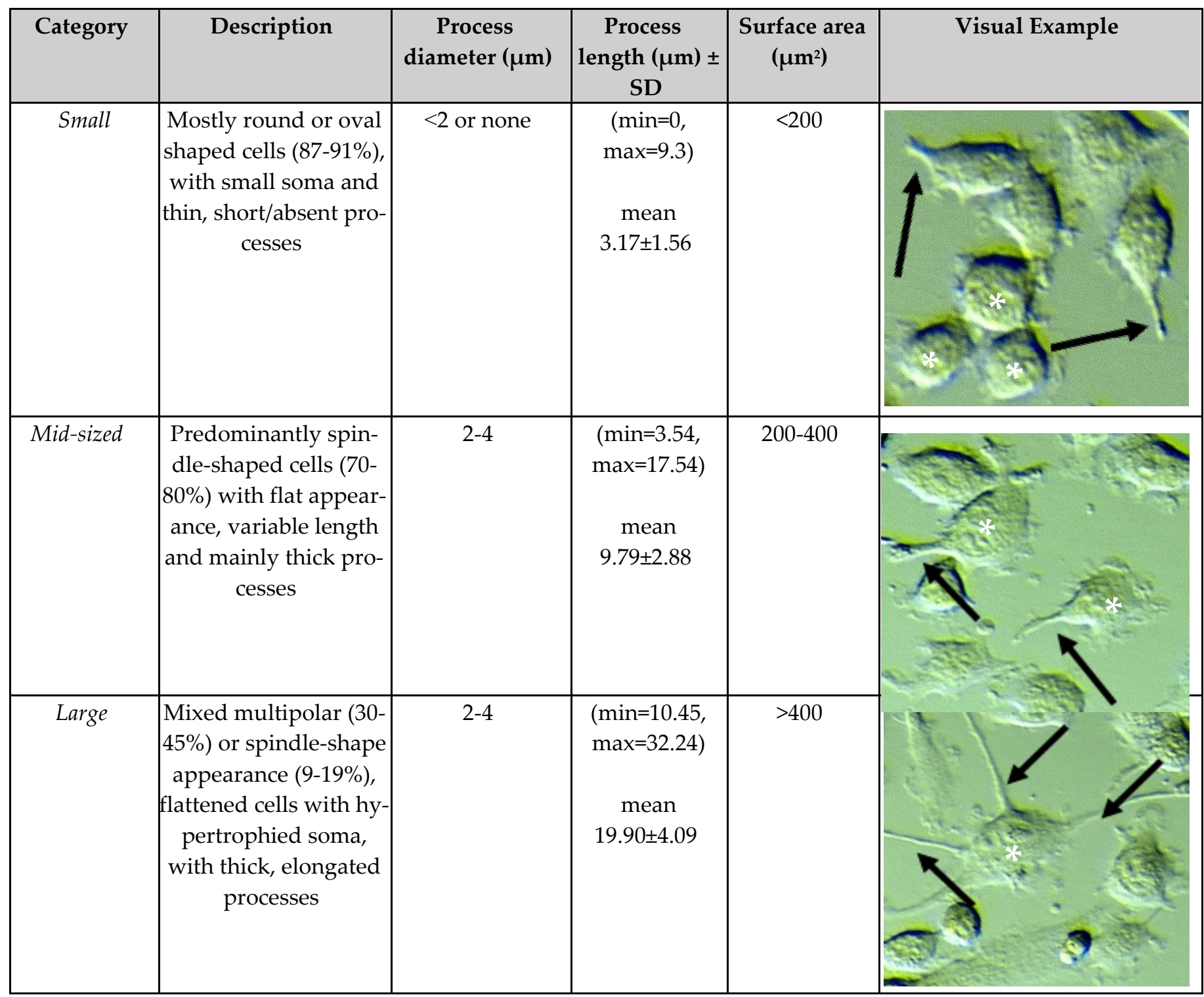

Criteria for assortment of BV2 cells into small, mid-sized and large cells. Descriptions are listed with an approximate visual example. Black arrows indicate cellular processes. White asterisks depict different morphologies of cells.

\subsection{PACAP and VIP differentially affect BV2 cell motility and urokinase plasminogen activator} ( $u P A)$ expression after LPS challenge

Microglia are highly motile cells that constantly monitor their microenvironment, they migrate quickly to sites of injury where they phagocytose debris and dying cells [58]. To determine if the distinct morphological changes observed after PACAP or VIP treatment were associated with functional changes, a scratch/wound healing assay was performed in BV2 cells exposed to LPS, in the presence or not, of PACAP or VIP.

LPS treatment almost completely abrogated cell motility in BV2 cells during the initial $24 \mathrm{~h}$, resulting in a significantly increased residual wound area in LPS Vs control cells ${ }^{* * *} \mathrm{p}<0.001$ both at 12 and $\left.24 \mathrm{~h}\right)$. Cell motility was partially recovered at $30 \mathrm{~h}(\mathrm{p}>0.05 \mathrm{Vs}$ control), however the percentage of wound area was still significantly larger than in controls at $36 \mathrm{~h}\left({ }^{* * *} \mathrm{p}<0.001 \mathrm{Vs}\right.$ control at 36h, Fig. 10a-b).

VIP treatment effectively reduced LPS-induced immobility, recording a significant reduction of the wound area at $12 \mathrm{~h}(\# \mathrm{p}<0.05 \mathrm{Vs}$ LPS $), 24 \mathrm{~h}(\# \# \mathrm{p}<0.001)$ and $36 \mathrm{~h}(\# \# \mathrm{p}<0.01)$ (Fig. 10a-b). 
Similar to VIP, treatment with PACAP also significantly increased the percentage of wound area closure starting from $12 \mathrm{~h}(\# \mathrm{p}<0.05$ Vs LPS), with further increases recorded at later time points (\#\#\# $<0.001$ Vs LPS at 24h, \#\#p<0.01 at 30h and \#\#p<0.01 at 36h, respectively, Fig. 10a-b). At 24 and 30h, the percentage of PACAP-induced wound closure was significantly higher than in VIP treated cells $(\$ \$ \$ \mathrm{p}<0.001$ Vs LPS+VIP at $24 \mathrm{~h}$ and $\$ \mathrm{p}<0.05$ Vs LPS+VIP at 30h, respectively) (Fig. 10a-b).

To provide the molecular basis to explain the different activities of PACAP and VIP on cell motility, we analysed the expression of urokinase-type plasminogen activator (uPA), a plasminogen cleaving enzyme known to be involved in cell migration [59]. Doseresponse studies with increasing concentrations of LPS $(0.1-10 \mu \mathrm{g} / \mathrm{mL})$ demonstrated that the inflammatory mimetic significantly down-regulated uPA mRNA expression at all doses tested $\left({ }^{* * *} \mathrm{p}<0.001\right)$ (Fig. 10c). PACAP treatment in LPS-treated cells significantly increased uPA mRNA (\#\#\#p<0.001 Vs LPS, Fig. 10d) and protein expression (\#\#\# $<0.001$, Fig. 10e), whereas VIP treatment failed to rescue LPS-induced downregulation of uPA mRNAs ( $p>0.05$ Vs LPS, Fig. 10d) but partly rescued uPA protein expression $(\# \# p<0.01 \mathrm{Vs}$ LPS, Fig. 10e). Of note, the different activities of PACAP and VIP on uPA mRNA and protein were both statistically significant ( $\$ p<0.05$ Vs LPS+VIP for both, Fig. 10d-e).

A
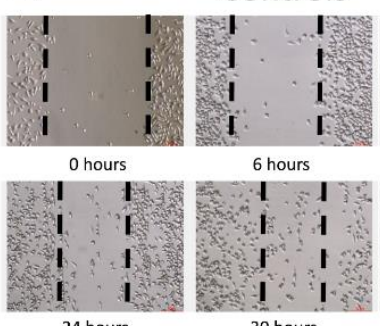
6 hours

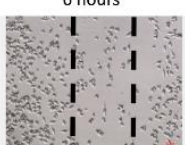

\section{Controls}

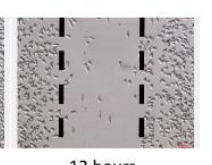
12 hours

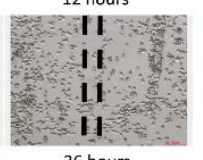

36 hours

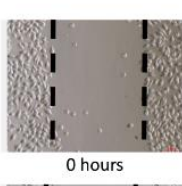

LPS $(1 \mu \mathrm{g} / \mathrm{ml})$
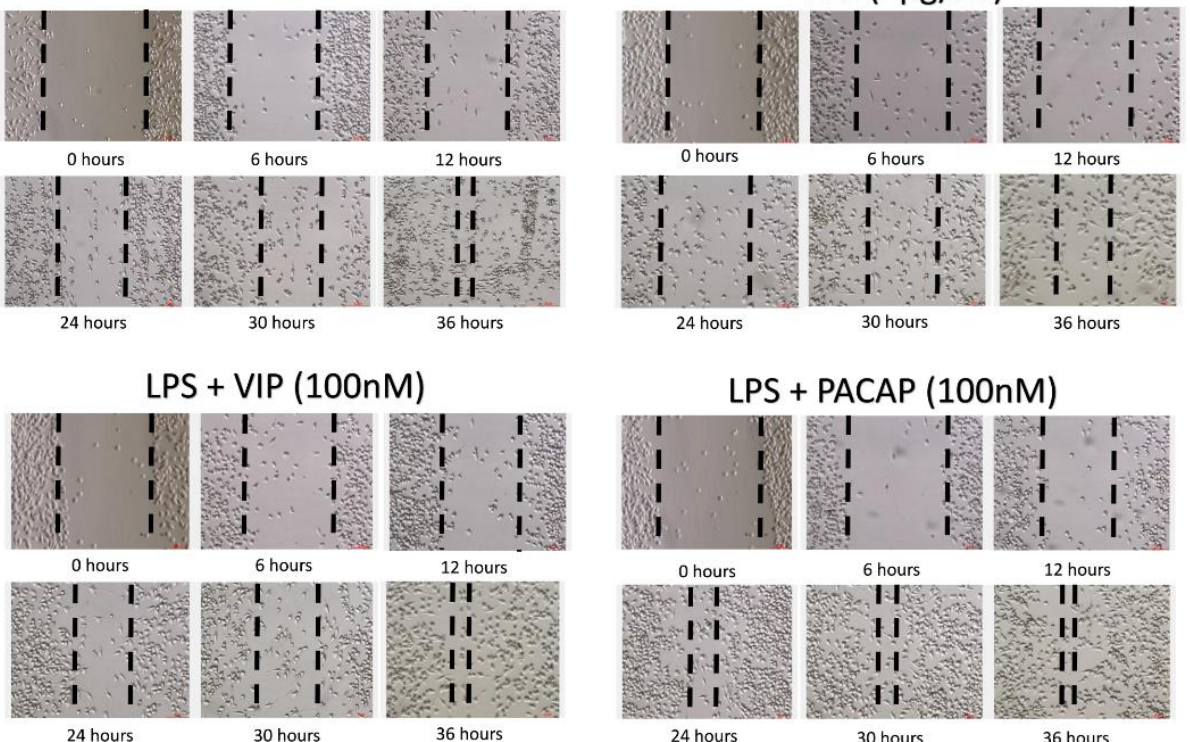

\section{C}

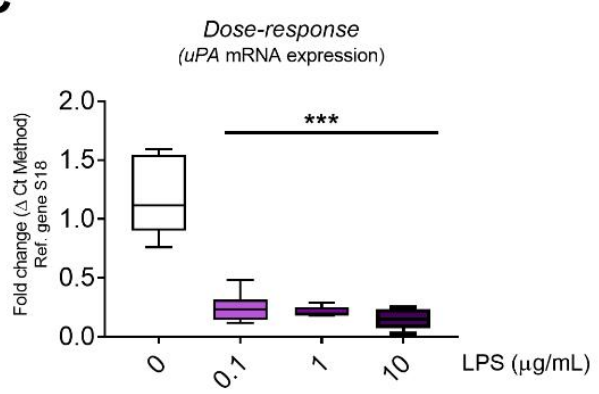

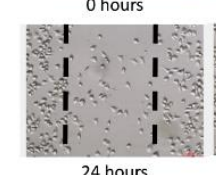

24 hours
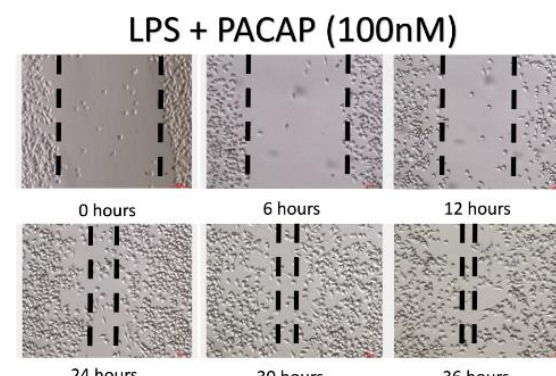

D

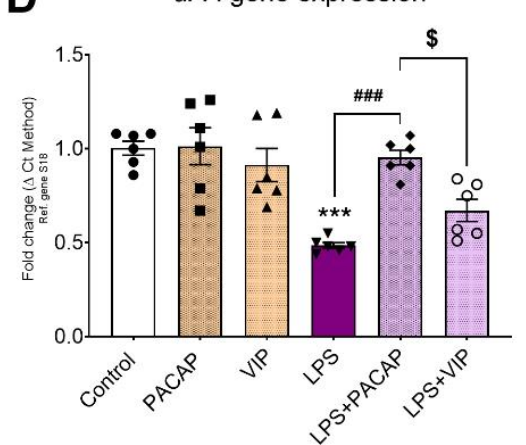

B

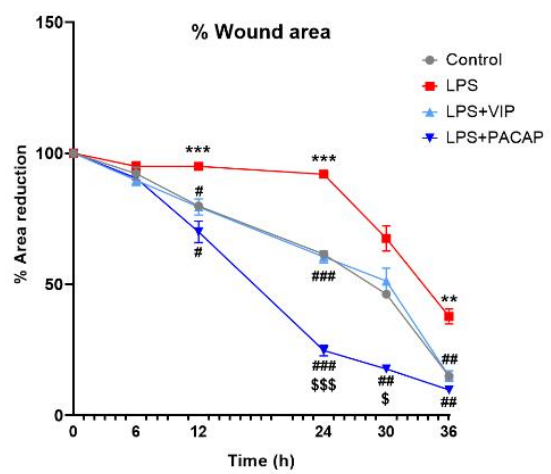

uPA protein expression
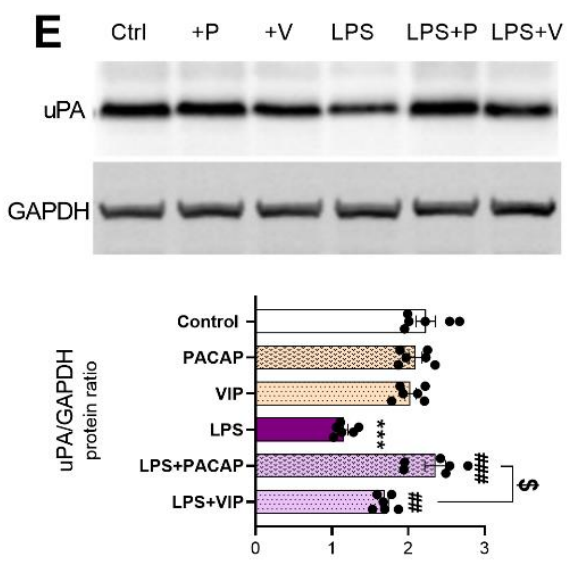

Figure 10. Effects of PACAP or VIP treatment on cell motility (wound healing assay) and uPA expression in LPS-treated BV2 cells. BV2 cells plated in 6-well plates and left to grow until 95\% confluent. A scratch was created in the centre of the well using a P1000 pipette tip and media replaced with indicated treatments: $1 \%$ FGM (Control), $1.0 \mu \mathrm{g} / \mathrm{ml} \mathrm{LPS}, 1.0 \mu \mathrm{g} / \mathrm{ml}$ LPS + PACAP 100nM and 1.0 $\mathrm{gg} / \mathrm{ml}$ LPS + VIP 100nM. (A) Images were taken over time at 0, 6, 12, 25, 30 and $36 \mathrm{~h}$ using Nikon Eclipse Ts2 inverted microscope. Black dashed lines delineate the wound area. Magnification $=20 \times$. Scale bar $=$ $60 \mu \mathrm{m}$. (B) Analyses were performed using Image J $1.51(\mathrm{NIH})$ software, where the area reduction was calculated. ${ }^{* *}$ p $<0.01$ 
or ${ }^{* * *} \mathrm{p}<0.001$ Vs time Control at the corresponding time point; $\# \mathrm{p}<0.05, \# \mathrm{p}<0.01$ or \#\#\# $<0.001$ Vs LPS at the corresponding time point; $\$ \mathrm{p}<0.05$ or $\$ \$ \$ \mathrm{p}<0.001 \mathrm{Vs}$ LPS+VIP. (C) Real time qPCR analyses showing the effects of increasing concentrations of LPS $(0,0.1,1$ and $10 \mu \mathrm{g} / \mathrm{mL}$ ) on uPA mRNA expression. (D and E) Real time qPCR and Western blot analyses depicting uPA mRNA and protein expression levels in BV2 cells exposed to LPS and treated with either PACAP or VIP at 24h. mRNA and protein levels of uPA are shown. Real time qPCR data represents means of $n=5-6$ biological replicates for each group, whereas Western blot data represents the mean of 4 independent experiments. Results are expressed as mean \pm SEM. ${ }^{* * *} \mathrm{p}<0.001$ vs control; $\# \mathrm{p}<0.05$, \#\#p<0.01 or \#\# $<<0.001$ vs LPS only; $\$ \mathrm{p}<0.05$ Vs LPS+VIP, as determined by oneway ANOVA followed by Tukey post-hoc test. uPA: urokinase plasminogen activator, GAPDH: Glyceraldehyde3-phosphate deyhydrogenase, S18: ribosomal protein subunit.

\section{Discussion}

In the present study we demonstrate that both PACAP and VIP exert potent immunosuppressive activities in BV2 microglial cells exposed to lipopolysaccharide (LPS), an inflammatory mimetic. By exposing healthy BV2 murine microglia cells to LPS, we attempt to replicate in vitro, the functions of resident microglial cell populations in response to stimulation by PAMPs or DAMPs. We show that the peptides downregulated the expression of a range of pro-inflammatory mediators following LPS induction whilst also altering gene expression for PACAP/VIP and their receptors. Additionally, morphological and morphometric evaluations of this cell line revealed patterns of phenotypic redistributions of cell subpopulations that were distinct for cells treated with either peptide during an LPS challenge. We report for the first time that, PACAP- or VIP-induced BV2 phenotypes are characterized by distinct effects on cell motility and the expression of uPA, an enzyme involved in regulating this biological function. When taken together, data from this study provide a better understanding of the mechanisms through which these naturally occurring peptides may dampen inflammation or affect cell surveillance functions by microglia.

Investigating the effects that LPS and peptide addition have on the PACAP/VIP family is pivotal to uncover individual peptide functions. In the literature, studies of PACAPdeficient mice have demonstrated that PACAP plays critical roles in the endogenous cytoprotective machinery. In these knockout phenotypes, mice show increased vulnerability to stressors in the nervous system, and they exhibit distinct morphological and behavioral abnormalities [60-62]. In our microglia cell model, the striking increases observed in Adcyap 1 expression in cells treated with VIP was an unexpected finding and given the well-known neuroprotective effect of the encoded peptide, we suggest a strong translational potential [63-65].

Despite their homology, VIP and PACAP genes have different promoters. PAC1 receptors that are able to couple to different signaling pathways are expressed in these cells, it would be expected therefore, that VIP and PACAP are able to control different biological activities. VIP is able to prevent activated microglia-induced neurodegeneration in models of brain trauma in mice, confirming its immune-modulatory role in vivo [48]. We surveyed levels of Vip mRNAs in response to immune challenge with LPS. The changes showed a marked recovery of expression following LPS+PACAP/VIP treatments in comparison to both resting and LPS only (Fig. 3a-b).

PAC1, VPAC1 and VPAC2 levels are diminished after LPS treatment and are partially restored by exogenous peptide supplementation. Adcyap1r1, also known as PAC1 receptor, has a higher affinity to PACAP over VIP. Studies in PAC1 receptor-knock out $(\mathrm{KO})$ mice demonstrate that endogenous PACAP and the activation of PAC1 receptor exerts anti-inflammatory effects, as the mice exhibited higher levels of $I L-6[66,67]$. Similarly, PACAP and VIP are more protective against the lethal effects of systemic LPS administration in wild-type mice, than in PAC1 receptor-KO mice through the activation of the receptor [66,67]. Our observations at the mRNA level show increased Adcyapr1r1 gene expression after treatment with LPS+PACAP/VIP in comparison with LPS only. Vipr1 and Vipr2, also known as VPAC1 and VPAC2 receptors, respectively, have equal high affinity 
for both PACAP and VIP peptides. Earlier studies show that by using a VPAC1 receptor agonist on LPS treated cells, it reduced TNF levels and IL-6 in vitro and also that VIP treatment was able to inhibit pro-inflammatory cytokine production from monocytes, mainly through the VPAC1 receptor [68]. VPAC2 KO mice exhibit exacerbated clinical, histopathological and immunological features of experimental autoimmune encephalomyelitis (EAE) in comparison to wild type (WT) mice [69]. In our studies, Vipr1 gene expression is upregulated post-LPS+PACAP/VIP treatment, and levels are increased in comparison with control and LPS only (Fig. 3d). Likewise, Vipr2 gene expression is upregulated post treatment (Fig. 3e). Nonetheless, in both animal and human models the selective activation of VPAC1 receptors has been shown to be more efficacious in controlling immune responses in comparison to VPAC2 [70]. Which may explain the trend that we observed within our study. It is reasonable then for us to hypothesize that the changes in the PA$\mathrm{CAP} /$ VIPergic system in BV2 cells result in a neuroprotective and immunomodulating influence on microglia, as there is increased activation of the receptors following LPS treatment and exogenous administration of PACAP and VIP. Furthermore, we confirm that both of the receptors are expressed, and at least one of these is functional in BV2 microglia cells. Further we show that receptor activity is inversely correlated with the extent of the immune insult, as when there is immune insult, there is decreased receptor expression.

The imbalance between the excessive pro-inflammatory and suppressed anti-inflammatory cascade processes is responsible for the consequent neurodegeneration and damage to microglia cells. Resting microglial cells lack or express only low levels of the inducible nitric oxide synthase (iNOS), the main enzyme capable of synthesizing nitric oxide (NO), so we anticipated that we wouldn't observe high expression of the gene in the control group [71]. The amounts of basal iNOS and NO observed in the control groups are likely attributable to constitutive activity in BV2 cells in response to the immortalisation process, which is obtained through the introduction of a retrovirus in the cell lineage [72,73]. Increased levels of NOS2 have been associated with brain inflammation and neurodegenerative diseases as the mechanism that activated microglia intoxicate neurons in culture has been suggested to involve the increased release of NO [54,74,75]. Reduction of neuronal cell death has been shown in studies utilizing iNOS inhibitors and knockout mice, resulting in protection of the animal to the immune challenge, conveying the neurotoxic effect of iNOS/NOS2 [76,77]. This is due to the fact that the iNOS promoter contains discreet regions where one is a NF- $\mathrm{KB}$ binding site, activated mainly by LPS [78,79]. In our studies, we saw decreased NOS2 expression in activated BV2 cells post-LPS+PACAP/VIP treatment affirming the anti-inflammatory capabilities of both PACAP and VIP (Fig. 4). This result was also confirmed through protein analyses. It is known that NO is released from microglia following exposure to LPS [80]. A finding further supported in our experiments, where the BV2 cells accumulated nitrite as a stable oxidized product of NO within the culture media when stimulated with LPS, and PACAP/VIP were able to inhibit this production (Fig. 6). These observations confirmed our hypotheses which were based on observations from previous studies that showed that PACAP/VIP had modulatory effect on iNOS through a reduction of NF-KB binding [81,82].

The release of inflammatory mediators, such as IL-1 $\beta, I L-6$ and Itgam defines the activation state of the cells. These inflammatory cytokines allow for the initiation of inflammatory cascade, and thus result in damage. In the present study, the levels of pro-inflammatory cytokines including IL-1 $\beta, I L-6$, Itgam, Adgre1 and CD68 were significantly increased with LPS and these levels were restored following treatments with the peptides (Fig. 5).

Another crucial step in the microglial injury response is the up-regulation of the specific microglia marker Iba1. AIF1 is the gene encoding Iba1, a binding peptide associated with microglial activation in the brain [83]. The specificity of Iba1 as a specific microglia 
marker is convincingly demonstrated by a study showing that while cultured hypothalamic neurons do not stain positively for Iba1, a massive $94 \%$ of cells in a primary culture of microglia were positively stained [84]. Iba1 expression in microglia is also shown to increase in models of brain disease whilst it remains low prior to disease presentation [35]. Similar to iNOS, our findings showed that Iba1 is also expressed at low levels by untreated control cells (Fig. 4). Which could again be due to the immortalised nature of the BV2 cell lineage, which may induce some spontaneous polarization of cells. Nonetheless, we present compelling experimental data that shows the up-regulation of AIF1/Iba1 after exposure to LPS and a clear down-regulation of its expression following treatment with PACAP or VIP (Fig. 4). These findings are seen at both mRNA (Fig. 4c) and protein levels (Fig. $\mathbf{4 a - b}$ ) and are also corroborated by immunocytochemical evidence (Fig. $\mathbf{4 f - g}$ ). This shows that, at least in vitro, PACAP and VIP modulate microglial activation. This observation could lead to potential options to dampen neurodegeneration. We also conclude that Iba1 is an early marker of microglial activation when accompanied by increases in $I L$ 6 and $I L-1 \beta$, as we observed coincident changes within $12 \mathrm{~h}$ of the onset of inflammation. These results are noteworthy given that both BV2 cells, and primary microglia express Iba1, enabling translation of PACAP and VIP abilities to primary microglia [80].

Transformation of cellular morphology is another crucial characteristic alerting to the presence of activation-induced change in microglia $[85,86]$. Such morphometric assessments may also aid in the identification of microglial functional state. We investigated changes in morphology, along with Iba1 staining in an attempt to unveil morphologi$\mathrm{cal} /$ morphometric patterns that could suggest changes in BV2 microglial activation or, perhaps other biological functions. Nevertheless, it is important to note that this is a novel morphometric approach and at present, not much supporting literature is available.

Morphometric analyses demonstrated that BV2 cells exhibited a range of sizes, with the cell surface areas ranging from as little as $7 \mu \mathrm{m}^{2}$ up to $924 \mu \mathrm{m}^{2}$. This prompted us assess whether the distribution of cell subpopulations varied across the treatment groups with distinctive and specific patterns. In our analyses we distinguished three clear subsets/categories of cell sizes (small cells $=<200 \mu \mathrm{m}^{2}$, mid-sized cells $=200-400 \mu \mathrm{m}^{2}$ and large cells $=$ $>400 \mu \mathrm{m}^{2}$ ), whose pattern of changes were affected by LPS exposure and importantly, that were found to be affected by PACAP or VIP treatment (Fig. 7). Using linear regression analyses we also determined that cell size correlated with the length of cellular processes (Fig. 8a), and that this relationship was maintained across each of the cell size categories (Fig. $\mathbf{8 b}$-d), supporting the suitability of this ranking method to classify BV2 cells according to size.

When BV2 cells were analyzed, using our classification method (ie., small; mid-sized; and large), the untreated cells were found to be predominantly small sized $(62.05 \%$, Fig. 7c). Exposure to LPS caused a major shift towards the population of large-sized cells (56.59\%, Fig. $7 \mathrm{~d}$ ) at the expenses of small cells (reduced to $12.05 \%$ by LPS), suggesting a correlation between cell size and polarization state. In line with the anti-inflammatory activities seen using PACAP, treatment of LPS-stimulated microglia with the peptide rescued the small cell subpopulation (54.09\%, Fig. 7e) and reduced the portion of large-sized cells (reduced from $15.91 \%$ ), supporting a possible correlation between microglial functional state (i.e. resting or activated) and soma size. Of note, the subpopulation of BV2 cells that was classified as mid-sized did not vary significantly among untreated, LPStreated or LPS+PACAP-treated cells (33.41\%, 31.36\% and 30\%, respectively, Fig. 7c-e). In contrast, VIP treatment only partly rescued the percentage of small-sized cells (28.18\%), whereas it caused a robust increase in the proportion of mid-sized cells $(48.41 \%$, Fig. $7 f)$.

Gross evaluation of BV2 cell morphology revealed a heterogeneous appearance of cells, which presented with three distinct phenotypes (i.e. rounded-, spindle/bipolar- or multipolar-shaped cells), all of which were associated with peculiar changes in processes 
length (short or elongated) and thickness (please refer to Table $\mathbf{1}$ for details). There was a uniform distribution of rounded, bipolar or multipolar cells across untreated, LPS-treated or LPS+PACAP-treated cells (Fig. 9a). Yet, similarly to morphometric results, only cells that were co-treated with LPS+VIP displayed a significant increase in the subset of cells exhibiting bipolar/spindle morphology (53\%, Fig. 9a), suggesting a possible relationship between the latter and cell size (mid-sized cells) under these experimental conditions.

To explore the possible link between BV2 cell morphology and size, cells were selected in function of their morphological appearance; cell surface areas were measured and ranked accordingly across the different treatment groups (Fig. 9b). Results demonstrated that most of the rounded cells (about 90\%), irrespective of treatment, were categorized as small-sized. Similarly, about $60-70 \%$ of cells with bipolar-shape fell into the midsize category, although in the LPS+VIP group the percentage of mid-sized cells went up to about $80 \%$ (Fig. 9b). Based on these findings, it is reasonable to suggest that BV2 microglia (and perhaps even primary microglia) are subject to a whole spectrum of morphological/morphometric changes that may be accompanied by increased or decreased cell functionality $[87,88]$.

Microglial cells are involved in many biological processes, including immune surveillance, phagocytosis, as well as tissue repair and cell migration $[14,89,90]$. Therefore, we assessed if the distinct morphological and morphometric changes seen after VIP but not PACAP treatment could be associated with distinct biological effects of either peptides. We focused our attention on cell mobility, as this function is associated strongly with changes in cell shape [91]. Additionally, previous studies have reported that PACAP reliably stimulates the expression and activity of the urokinase plasminogen activator, an enzyme involved in microglial mobility [92], both in peripheral glial cells [93] and the prefrontal cortex and hippocampus of mice [94]. To our surprise, evaluation of cell motility, measured using the wound healing/scratch assay, revealed that PACAP was more effective than VIP in reinstating cell mobility after an LPS challenge (Fig. 10a-b). Furthermore, PACAP completely rescued LPS-induced reduction of uPA expression, whereas VIP was only partly effective (Fig. 10d-e). Based on these findings, it cannot be excluded that mid-sized bipolar shaped BV2 cells subpopulations may be less motile than the counterpart and/or contribute to hinder the overall microglial motility, although this warrants further investigations. We also identified a mechanism by which PACAP, more effectively than VIP, stimulates uPA expression to restore cell mobility, suggesting that uPA itself may be able to affect BV2 cell morphology, size and consequently, motility. However, additional investigations are needed to confirm this theory.

In conclusion, our investigations have demonstrated that both PACAP and VIP are two potent immune modulatory peptides that should be considered further as potential targets for treatment of neurodegenerative conditions, especially when an inflammatory component is present. In BV2 microglia, PACAP or VIP stimulation during an LPS challenge reliably reduced the expression of pro-inflammatory cytokines, microglial activation markers and NO release. Furthermore, treatment with these peptides triggered distinct changes in the morphology and size of cells, which were in parallel with distinct abilities of PACAP or VIP to stimulate cell migration/motility.

Our findings corroborate the idea that PACAP or VIP can exert distinctive regulatory activities on certain aspects of microglial function, and reveal different implications for the use of one ligand over the other for therapeutic purposes. Such differences are likely to be explained by the different binding activities of PACAP and VIP to their receptors.

\section{Materials and Methods}

\subsection{Cell Culture}


The study was carried out in murine microglial cells, BV2 kindly provided by Dr Eryn Werry from the University of Sydney, Sydney, Australia. Cells were cultured in Dulbecco's modified Eagle's medium (DMEM) supplemented with either 1\% or 10\% heat-inactivated fetal bovine serum (FBS) and $1 \%$ penicillin $(100 \mathrm{IU} / \mathrm{ml}) /$ streptomycin $(100 \mu \mathrm{g} / \mathrm{ml})$ (Sigma-Aldrich, USA). Cells were incubated at $37^{\circ} \mathrm{C}$ in a humidified atmosphere with $5 \%$ CO2. After seeding at a density of $4 \times 10^{5}$ cells for $24 \mathrm{~h}$, BV2 cells were serum starved for a further $24 \mathrm{~h}$ in media containing $1 \%$ FBS prior to treatments.

Cells were subjected to different treatments: 1) Control, 2) 100nM PACAP (SigmaAldrich, USA), 3) 100nM VIP (AusPep, Australia), 4) 1 $1 \mu \mathrm{g} / \mathrm{ml}$ LPS (Sigma-Aldrich, St. Louis, MO), 5) LPS + PACAP and 6) LPS + VIP. Thereafter, cells were harvested at 6, 12, 24 or $48 \mathrm{~h}$ for downstream molecular analyses.

\subsection{Quantitative real time polymerase chain reaction}

Total RNA extracts from harvested cells were subjected under certain treatments $(\mathrm{n}=3-6)$ and isolated using $1 \mathrm{ml}$ TRIsureTM reagent (Bioline, AUS), $0.2 \mathrm{ml}$ chloroform and precipitated with $0.5 \mathrm{ml}$ isopropanol (Sigma). Pellet was washed with $75 \%$ ethanol and air dried by inversion of tubes. Total RNA $(1 \mu \mathrm{g})$ was diluted in milliQ H2O to a final volume of $11 \mu \mathrm{l}$. $9 \mu \mathrm{l}$ of Tetro cDNA synthesis mix (Bioline, NSW, Australia) was added to each $11 \mu \mathrm{l}$ aliquot, each containing: $1 \mu \mathrm{l}$ oligo $(\mathrm{dT}) 18$ primers, $1 \mu \mathrm{l}$ random hexamer primers mix, $1 \mu \mathrm{l} 10 \mathrm{mM}$ dNTP mix, $4 \mu 15 \times$ RT buffer, $1 \mu \mathrm{l}$ RNase inhibitor and $1 \mu l$ reverse transcriptase. $20 \mu \mathrm{l}$ of each sample were then incubated at $25^{\circ} \mathrm{C}$ for $10 \mathrm{~min}$, followed by $45^{\circ} \mathrm{C}$ for $30 \mathrm{~min}$. Reaction was terminated by incubation of samples at $85^{\circ} \mathrm{C}$ for $5 \mathrm{~min}$.

Aliquots of cDNA were amplified using specific primers shown in Table 2. HardShell@ 96-Well PCR plates (Bio-Rad, Hercules, CA) were utilised, and up to 4 genes were tested per each run. Each PCR reaction mix was prepared in a final volume of $7 \mu \mathrm{l}$, to which we added $3 \mu \mathrm{l}$ of cDNA (final concentration $=30 \mathrm{ng}$ ) and conducted using the CFX96 Touch $^{\mathrm{TM}}$ Real-Time PCR Detection System (Bio-Rad, Hercules, CA). Each PCR reaction mix contained $5 \mu \mathrm{l}$ SensiFAST SYBR No-ROX kit (Bioline, NSW, Australia), 0.8 $\mu 15 \mu \mathrm{M}$ forward primer, $0.8 \mu \mathrm{l} 5 \mu \mathrm{M}$ reverse primer and $0.4 \mu \mathrm{l}$ milliQ $\mathrm{H}_{2} \mathrm{O}$. PCR was performed using the following settings:

1) $95^{\circ} \mathrm{C}$ for $\left.2 \mathrm{~min}, 2\right) 60^{\circ} \mathrm{C}$ for $\left.10 \mathrm{sec}, 3\right) 72^{\circ} \mathrm{C}$ for $\left.10 \mathrm{sec}, 4\right)$ Plate read, 5) Repeat step 2 for 45 cycles, 6) $65^{\circ} \mathrm{C}$ for $\left.35 \mathrm{sec}, 7\right)$ Plate read and 8) Repeat step $6 \times 60$ times using the PCR instrument. After the protocol was completed, the $\mathrm{Ct}$ values were exported and analysed. Relative changes in gene expression were computed using the comparative Ct method [51]. The formula $2^{-\Delta \Delta \mathrm{Ct}}$ was used to calculate fold changes. Baseline measurements for untreated controls were set to 1 .

Table 2. Primer sequences used for RT-qPCR.

\begin{tabular}{|c|c|c|c|}
\hline Gene & Forward & Reverse & bp length \\
\hline $\begin{array}{c}\text { Adcyap1 } \\
\text { Acc\# NM_009625.2 }\end{array}$ & CTGCGTGACGCTTACGCCCT & CCTAGGTTCTCCCCCGCGCC & 152 \\
\hline $\begin{array}{c}\text { Vip } \\
\text { Acc\# NM_011702.2 }\end{array}$ & TGGCAAACGAATCAGCAGCAGCA & AGCCATTTGCTTTCTGAGGCGGG & 106 \\
\hline $\begin{array}{c}\text { Adcyap1r1 } \\
\text { Acc\# NM_007407.3 }\end{array}$ & CAGTCCCCAGACATGGGAGGCA & AGCGGGCCAGCCGTAGAGTA & 139 \\
\hline $\begin{array}{c}\text { Vipr1 } \\
\text { Acc\# NM_011703.4 }\end{array}$ & TCAATGGCGAGGTGCAGGCAG & TGTGTGCTGCACGAGACGCC & 127 \\
\hline Vipr2 & GCGTCGGTGGTGCTGACCTG & ACACCGCTGCAGGCTCTCTGAT & 155 \\
Acc\# NM_009511.2 & & & 164 \\
\hline IL-1 3 Acc\# NM_008361.4 & GCTACCTGTGTCTTTCCCGT & CATCTCGGAGCCTGTAGTGC & \\
\hline
\end{tabular}




\begin{tabular}{|c|c|c|c|}
\hline $\begin{array}{c}I L-6 \\
\text { Acc\# NM_031168.2 }\end{array}$ & ССССААТTТССААТGСТСТСС & CGCACTAGGTTTGCCGAGTA & 141 \\
\hline $\begin{array}{c}I L-10 \\
\text { Acc\# NM_010548.2 }\end{array}$ & GCATGGCCCAGAAATCAAGG & GAGAAATCGATGACAGCGCC & 91 \\
\hline $\begin{array}{c}\text { Itgam } \\
\text { Acc\# NM_001082960.1 }\end{array}$ & GAGCAGGGGTCATTCGCTAC & GCTGGCTTAGATGCGATGGT & 94 \\
\hline $\begin{array}{c}\text { Adgre1 } \\
\text { Acc\# NM_001355722.1 }\end{array}$ & GCTTATGCCACCTGCACTGA & GGTGAGTCACTTTGAAGACATTCG & 143 \\
\hline $\begin{array}{c}\text { AIF1 } \\
\text { Acc\# NM_001361501.1 }\end{array}$ & GCTTTTGGACTGCTGAAGGC & GCTTCAAGTTTGGACGGCAG & 114 \\
\hline $\begin{array}{c}\text { CD68 } \\
\text { Acc\# NM_001291058.1 }\end{array}$ & СТСССАССACAAATGGCACT & CTTGGACCTTGGACTAGGCG & 95 \\
\hline $\begin{array}{c}\text { NOS2 } \\
\text { Acc\# NM_010927.4 }\end{array}$ & AATCTTGGAGCGAGTTGTGG & CAGGAAGTAGGTGAGGGCTTG & 139 \\
\hline $\begin{array}{c}u P A \\
\text { Acc\# NM_008873.3 }\end{array}$ & CATCCATCCAGTCCTTGCGT & TTTCATGGTAGTGCCGCTGG & 87 \\
\hline $\begin{array}{c}\text { S18 } \\
\text { Acc\# NM_011296.2 }\end{array}$ & CCCTGAGAAGTTCCAGCACA & GGTGAGGTCGATGTCTGCTT & 145 \\
\hline
\end{tabular}

Forward and reverse primers were chosen from the $5^{\prime}$ and $3^{\prime}$ region of each gene messenger ribonucleic acid (mRNA). The right column displays the expected length of each PCR amplification product.

\subsection{Western blot analysis}

Protein lysate were homogenised in RIPA buffer (Sigma-Aldrich, St. Louis, MO), which was supplemented with cOmplete ${ }^{\mathrm{TM} U L T R A}$ protease inhibitor cocktail (Roche Life Science, North Ryde, NSW). Lysates were then sonicated twice at $50 \%$ power for $10 \mathrm{sec}$ using an ultrasonic probe, followed by centrifugation prior to protein quantification. Protein concentrations were determined using the Bicinchoninic Acid (BCA) Assay Kit (ThermoFisher Scientific, Waltham, MA).

Protein samples $(15 \mu \mathrm{g})$ were separated by sodium dodecyl sulfate (SDS)-polyacrylamide gel electrophoresis (SDS-PAGE) using 4-20\% Mini-PROTEAN® ${ }^{\circledR}$ TGX Stain-Free ${ }^{\text {TM }}$ protein gels (15 wells) (Bio-Rad, Hercules, CA). Samples were prepared by $3.75 \mu$ of $4 \times$ Laemmli buffer (Bio-Rad, Hercules, CA) and $\beta$-mercaptoethanol (Sigma-Aldrich, St. Louis, MO) mix (Laemmli buffer 20:1 with $\beta$-mercaptoethanol) to a final volume of $15 \mu$. Samples were then denatured at $70^{\circ} \mathrm{C}$ for $10 \mathrm{~min}$ using the $\mathrm{T} 100^{\mathrm{TM}}$ thermal cycler.

Proteins $(15 \mu \mathrm{g})$ were resolved on gels and transferred to a PVDF membrane using the semi-dry approach (Trans-Blot Turbo ${ }^{\text {TM }}$ Transfer Pack; Bio-Rad, Hercules, CA). Once proteins were transferred, the membrane was removed from the apparatus and briefly washed in tris-buffered saline containing Tween ${ }^{2} 20$ (TBST) $1 \times$ three times before blocking with $5 \%$ blocking buffer containing $5 \%$ skim milk in TBST $1 \times$ for $1 \mathrm{~h}$ at room temperature at 55-60rpm. The membranes were probed with anti-rabbit primary antibodies recognizing either Iba1, iNOS or GAPDH (used as loading control) overnight at $4^{\circ} \mathrm{C}$ under gentle oscillation (55rpm) (for a full list of the antibodies used please refer to Table 3). Following incubation, membranes were washed thoroughly. Finally, membranes were incubated with secondary antibodies for $1 \mathrm{~h}$ at room temperature and washed again before imaging. To visualize immunoreactive bands, we used Clarity ${ }^{\mathrm{TM}}$ Western ECL Blotting Substrate

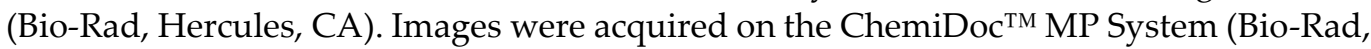
Hercules, CA). Band intensities were quantified using ImageJ software and values were normalized to GAPDH. 
Table 3. Antibodies used in Western Blots.

\begin{tabular}{|c|c|c|c|}
\hline Antibody & Source & Predicted Band Size & Dilution \\
\hline PLAU & LS-C193095 & $55 \mathrm{kDa}$ & $1: 1000$ \\
\hline Iba1 & GTX100042, GeneTex & $17 \mathrm{kDa}$ & $1: 300$ \\
\hline iNOS & GTX60599, GeneTex & $32 \mathrm{kDa}$ & $1: 1000$ \\
\hline GAPDH & VPA00187, Bio-Rad & $37 \mathrm{kDa}$ & $1: 1500$ \\
\hline $\begin{array}{c}\text { Goat anti Rabbit IgG } \\
\text { HRP (Secondary) }\end{array}$ & STAR208P, Bio-Rad & & $1: 20000$ \\
\hline
\end{tabular}

Antibodies used for Western Blots and their predicted molecular weights are shown. All primary antibodies are raised in rabbit and are polyclonal. The dilutions used are depicted in the right column.

\subsection{Immunocytochemistry}

BV2 microglial cells were grown on cover slips pre-coated in poly-l-lysine (SigmaAldrich, St. Louis, MO) and fixed with 4\% paraformaldehyde (PFA) (Sigma-Aldrich, St. Louis, MO). Then, cells were permeabilised in PBS containing 0.25\% Triton X-100 (SigmaAldrich, St. Louis, MO) for $10 \mathrm{~min}$ and then rinsed with PBS. Thereafter, fixed cells were treated with blocking solution (PBS, $1 \%$ bovine serum albumin [Sigma-Aldrich, St. Louis, $\mathrm{MO}$ ] and $0.1 \%$ Tween ${ }^{\circledR 20}$ ) for $30 \mathrm{~min}$. Blocking serum was replaced with appropriately diluted primary antibody (in PBS) (polyclonal anti-rabbit Iba1 antibody; GeneTex, Irvine, CA) and incubated at $4^{\circ} \mathrm{C}$ overnight with gentle agitation. Cells were rinsed with PBS for 3 changes for $5 \mathrm{~min}$ each. $1 \mathrm{ml}$ of appropriately diluted fluorescin-conjugated secondary antibody (in PBS) (Anti-rabbit IgG FAb2 Alexa Fluor ${ }^{\circledR} 488$ molecular probes; Cell Signalling Techology, Danvers, MA) was applied to the wells and incubated at room temperature for 1 hour protected from light. Following the secondary antibody incubation, cells were washed with PBS. $0.3 \mu \mathrm{g} / \mathrm{ml}$ DAPI stain (Cell Signalling Techology, Danvers, MA) was applied to the cells for $1 \mathrm{~min}$ and discarded. Cells were washed again with PBS and then coverslips were mounted onto one-frosted ended microscope slides (Australian Scientific, NSW, Australia) using mounting medium (ProLong ${ }^{\circledR}$ Gold Antifade Reagent; Cell Signalling Techology, Danvers, MA). Clear nail polish was applied to the edges of the coverslips to ensure that they remain secure and sealed. Colours of antibody staining were observed with the Delta Vision Elite deconvolution microscope.

\subsection{Nitrite Assay}

Levels of nitric oxide $(\mathrm{NO})$ in culture supernatants were quantified by the utilisation of the Griess reaction. Briefly, BV2 cells $\left(5 \times 10^{5}\right)$ were seeded in $25 \mathrm{~cm}^{2}$ flasks and starved in $1 \%$ FGM for $24 \mathrm{~h}$, prior to initiating the six treatments for $12 \mathrm{~h}$. Following treatments, culture media was replaced with freshly prepared media not containing any treatment and cells were incubated for a further $24 \mathrm{~h}$ to allow accumulation of NO. Twenty-four hours later, the supernatant was aspirated and collected. Griess reagent (Sigma-Aldrich, St. Louis, MO) was prepared by dissolving $1 \mathrm{~g}$ Griess reagent in $25 \mathrm{ml}$ milliQ $\mathrm{H}_{2} \mathrm{O}(1: 25$ $\mathrm{w} / \mathrm{vol}$ ) in an autoclaved bottle shielded from the light. Under sterile conditions, $100 \mu \mathrm{l}$ of conditioned media was added into a 96 well plate, using at least 6 replicates from each group. Each experiment was repeated at least twice. $100 \mu \mathrm{l}$ of Griess reagent was added to each well containing 100ul of conditioned media from each group. The plate was incubated at room temperature for $15 \mathrm{~min}$ protected from light. Absorbance using a $540 \mathrm{~nm}$ filter was measured by the Tecan infinite M1000 Pro ELISA reader which reflected nitrite levels. Changes in NO were normalized to that of untreated cells and are expressed as percentage of controls. 


\subsection{Morphological Analyses}

BV2 cells $\left(5 \times 10^{5}\right)$ were seeded in $25 \mathrm{~cm}^{2}$ flasks and starved in $1 \%$ FGM for $24 \mathrm{~h}$, prior to initiating treatments: Control, LPS only, LPS+100nM PACAP and LPS+100nM VIP for 12h. Images were then captured using a Nikon Eclipse TS2 inverted microscope and subjected to morphological assortment and analyses (magnification 20×). Four experimenters blind to the cell culture conditions were assigned random images to analyse. After measuring the average diameter and length of cellular processes, along with soma surface area (average measurements from 450 individual cells) and assessing the gross morphology (i.e. flattened cell body, multipolar/bipolar/rounded shape), cells were then grouped into three different categories: a) small, b) mid-sized, and c) large cells (please see Table 1). Analyses of microscope images were performed using Image 1.51 (NIH, Bethesda, MD; available at http://rsb.info.nih.gov.ezproxy.lib.uts.edu.au/ij/), where cells were labelled and measured individually.

\subsection{Wound healing assay}

BV2 cells were seeded onto 6-well plates at a density of $1 \times 10^{5}$ cells $/ \mathrm{mL}$ and left until they were $90-95 \%$ confluent. Scratches were created using a P1000 pipette tip to scratch a straight line on the culture plate, reference lines on the bottom of the plate were used for alignment and to obtain the same field for each image. PBS was used to remove detached cells. Fresh media with indicated treatments was added: Control, LPS only, LPS+100nM PACAP and LPS+100nM VIP. Images were then captured at 0, 6, 12, 24, 30 and 36h using a Nikon Eclipse TS2 inverted microscope. The scratch area was determined and used to calculate $\%$ area reduction over time using ImageJ.

\subsection{Statistical analysis}

Data was analysed using GraphPad Prism ${ }^{\circledR}$ version 7.02 software (GraphPad Software Inc., La Jolla, CA, USA). All data were tested for normality with the KolmogorovSmirnov test. All variables were normally distributed. Data sets are reported as mean \pm standard error of mean (SEM). One-way or two-way repeated measures (RM) analysis of variance (ANOVA) followed by post-hoc tests (as appropriate) were utilised to assess which groups were statically different. Result for all statistical tests were considered significant when $\mathrm{p} \leq 0.05$.

Author Contributions: Conceptualization, A.C; methodology, A.C, J.K.; formal analysis, A.C., J.K. and G. A-B; data curation, J.K., S.T.B and A.C ; writing-original draft preparation, J.K.; writingreview and editing, A.C, J.A.W, K.A.K, S.T.B; supervision, A.C.; project administration, A.C.; funding acquisition, A.C. All authors have read and agreed to the published version of the manuscript.

Funding: This study was funded by the Rebecca L. Cooper Medical Research Foundation (Grant no. PG2020710) and the UTS - Start-up Grant 2018 to Associate Professor Castorina.

Acknowledgments: These experiments were completed using equipment and technical support from the Microscopy imaging facility, MIF at UTS. We would like to thank A/Prof. Louise Cole for the guidance in microscopy experiments.

Conflicts of Interest: The authors declare no conflict of interest. 


\section{References}

1. Nakagawa, Y.; Chiba, K. Role of microglial $\mathrm{m} 1 / \mathrm{m} 2$ polarization in relapse and remission of psychiatric disorders and diseases. Pharmaceuticals 2014, 7, 1028-1048.

2. Thameem Dheen, S.; Kaur, C.; Ling, E.-A. Microglial activation and its implications in the brain diseases. Current medicinal chemistry 2007, 14, 1189-1197.

3. Blander, J.M.; Medzhitov, R. Toll-dependent selection of microbial antigens for presentation by dendritic cells. Nature 2006, 440,808 .

4. Olson, J.K.; Miller, S.D. Microglia initiate central nervous system innate and adaptive immune responses through multiple tlrs. The Journal of Immunology 2004, 173, 3916-3924.

5. Caito, S.W.; Milatovic, D.; Hill, K.E.; Aschner, M.; Burk, R.F.; Valentine, W.M. Progression of neurodegeneration and morphologic changes in the brains of juvenile mice with selenoprotein p deleted. Brain research 2011, 1398, 1-12.

6. Gorman, A.M. Neuronal cell death in neurodegenerative diseases: Recurring themes around protein handling. Journal of Cellular and Molecular Medicine 2008, 12, 2263-2280.

7. Procaccini, C.; Santopaolo, M.; Faicchia, D.; Colamatteo, A.; Formisano, L.; De Candia, P.; Galgani, M.; De Rosa, V.; Matarese, G. Role of metabolism in neurodegenerative disorders. Metabolism 2016, 65, 1376-1390.

8. Sochocka, M.; Diniz, B.S.; Leszek, J. Inflammatory response in the cns: Friend or foe? Molecular neurobiology 2017, 54, 80718089.

9. Block, M.L.; Hong, J.-S. Microglia and inflammation-mediated neurodegeneration: Multiple triggers with a common mechanism. Progress in Neurobiology 2005, 76, 77-98.

10. Gao, H.-M.; Hong, J.-S. Why neurodegenerative diseases are progressive: Uncontrolled inflammation drives disease progression. Trends in Immunology 2008, 29, 357-365.

11. Carniglia, L.; Ram; \#xed; rez, D.; Durand, D.; Saba, J.; Turati, J.; Caruso, C.; Scimonelli, T.N.; Lasaga, M. Neuropeptides and microglial activation in inflammation, pain, and neurodegenerative diseases. Mediators of Inflammation 2017, $2017,23$.

12. Colton, C.A.; Mott, R.T.; Sharpe, H.; Xu, Q.; Van Nostrand, W.E.; Vitek, M.P. Expression profiles for macrophage alternative activation genes in ad and in mouse models of ad. J Neuroinflammation 2006, 3, 27.

13. Hong, H.; Kim, B.S.; Im, H.-I. Pathophysiological role of neuroinflammation in neurodegenerative diseases and psychiatric disorders. International Neurourology Journal 2016, 20, S2-7.

14. Norden, D.M.; Muccigrosso, M.M.; Godbout, J.P. Microglial priming and enhanced reactivity to secondary insult in aging, and traumatic cns injury, and neurodegenerative disease. Neuropharmacology 2015, 96, 29-41.

15. Ponomarev, E.D.; Maresz, K.; Tan, Y.; Dittel, B.N. Cns-derived interleukin-4 is essential for the regulation of autoimmune inflammation and induces a state of alternative activation in microglial cells. Journal of Neuroscience 2007, $27,10714-10721$.

16. Pott Godoy, M.C.; Tarelli, R.; Ferrari, C.C.; Sarchi, M.I.; Pitossi, F.J. Central and systemic il-1 exacerbates neurodegeneration and motor symptoms in a model of parkinson's disease. Brain : a journal of neurology 2008, 131, 1880-1894.

17. Rojo, A.I.; Innamorato, N.G.; Martín-Moreno, A.M.; De Ceballos, M.L.; Yamamoto, M.; Cuadrado, A. Nrf2 regulates microglial dynamics and neuroinflammation in experimental parkinson's disease. Glia 2010, 58, 588-598.

18. Smith, P.F. Inflammation in parkinson's disease: An update. Current opinion in investigational drugs (London, England: 2000) 2008, 9, 478-484.

19. Bernier, L.P.; Bohlen, C.J.; York, E.M.; Choi, H.B.; Kamyabi, A.; Dissing-Olesen, L.; Hefendehl, J.K.; Collins, H.Y.; Stevens, B.; Barres, B.A., et al. Nanoscale surveillance of the brain by microglia via camp-regulated filopodia. Cell reports 2019, 27, 2895-2908.e2894. 
20. Town, T.; Nikolic, V.; Tan, J. The microglial" activation" continuum: From innate to adaptive responses. J Neuroinflammation 2005, $2,24$.

21. Tang, Y.; Le, W. Differential roles of $\mathrm{m} 1$ and $\mathrm{m} 2$ microglia in neurodegenerative diseases. Molecular neurobiology 2016, 53, 1181-1194.

Stertz, L.; Magalhães, P.V.S.; Kapczinski, F. Is bipolar disorder an inflammatory condition? The relevance of microglial activation. Current Opinion in Psychiatry 2013, 26.

23. Colton, C.A. Heterogeneity of microglial activation in the innate immune response in the brain. Journal of neuroimmune pharmacology 2009, 4, 399-418.

24. Laskin, D.L. Macrophages and inflammatory mediators in chemical toxicity: A battle of forces. Chemical research in toxicology 2009, 22, 1376-1385.

25. Hernangómez, M.; Carrillo-Salinas, F.J.; Mecha, M.; Correa, F.; Mestre, L.; Loría, F.; Feliú, A.; Docagne, F.; Guaza, C. Brain innate immunity in the regulation of neuroinflammation: Therapeutic strategies by modulating $\mathrm{cd} 200$-cd200r interaction involve the cannabinoid system. Current pharmaceutical design 2014, 20, 4707-4722.

26. Bogie, J.F.; Stinissen, P.; Hellings, N.; Hendriks, J.J. Myelin-phagocytosing macrophages modulate autoreactive $t$ cell proliferation. J Neuroinflammation 2011, 8, 85.

27. Cagnin, A.; Kassiou, M.; Meikle, S.; Banati, R. In vivo evidence for microglial activation in neurodegenerative dementia. Acta Neurologica Scandinavica 2006, 114, 107-114.

28. Trapp, B.D.; Peterson, J.; Ransohoff, R.M.; Rudick, R.; Mörk, S.; Bö, L. Axonal transection in the lesions of multiple sclerosis. New England Journal of Medicine 1998, 338, 278-285.

29. Bai, L.; Zhang, X.; Li, X.; Liu, N.; Lou, F.; Ma, H.; Luo, X.; Ren, Y. Somatostatin prevents lipopolysaccharide-induced neurodegeneration in the rat substantia nigra by inhibiting the activation of microglia. Molecular medicine reports 2015, 12, 1002-1008.

30. Castorina, A.; Scuderi, S.; D’Amico, A.G.; Drago, F.; D'Agata, V. Pacap and vip increase the expression of myelin-related proteins in rat schwannoma cells: Involvement of pac1/vpac2 receptor-mediated activation of pi3k/akt signaling pathways. Experimental cell research 2014, 322, 108-121.

31. Castorina, A.; Tiralongo, A.; Giunta, S.; Carnazza, M.L.; Rasi, G.; D'Agata, V. Pacap and vip prevent apoptosis in schwannoma cells. Brain research 2008, 1241, 29-35.

32. Dejda, A.; Sokolowska, P.; Nowak, J.Z. Neuroprotective potential of three neuropeptides pacap, vip and phi. Pharmacological reports : PR 2005, 57, 307-320.

33. Delgado, M.; Jonakait, G.M.; Ganea, D. Vasoactive intestinal peptide and pituitary adenylate cyclase-activating polypeptide inhibit chemokine production in activated microglia. Glia 2002, 39, 148-161.

34. Gozes, I.; Brenneman, D.E. Vip: Molecular biology and neurobiological function. Molecular neurobiology 1989, 3, $201-236$.

35. Ringer, C.; Büning, L.-S.; Schäfer, M.K.; Eiden, L.E.; Weihe, E.; Schütz, B. Pacap signaling exerts opposing effects on neuroprotection and neuroinflammation during disease progression in the sod1 (g93a) mouse model of amyotrophic lateral sclerosis. Neurobiology of disease 2013, 54, 32-42.

36. Waschek, J. Vip and pacap: Neuropeptide modulators of cns inflammation, injury, and repair. British journal of pharmacology 2013, 169, 512-523.

37. Nowak, J.Z.; Zawilska, J.B. Pacap in avians: Origin, occurrence, and receptors-pharmacological and functional considerations. Current pharmaceutical design 2003, 9, 467-481.

38. Sherwood, N.M.; Krueckl, S.L.; McRory, J.E. The origin and function of the pituitary adenylate cyclase-activating polypeptide (pacap)/glucagon superfamily. Endocrine reviews 2000, 21, 619-670.

39. Delgado, M.; Leceta, J.; Ganea, D. Vasoactive intestinal peptide and pituitary adenylate cyclase-activating polypeptide inhibit the production of inflammatory mediators by activated microglia. Journal of Leukocyte Biology 2003, 73, 155-164. 
40. Grimaldi, M.; Cavallaro, S. Functional and molecular diversity of pacap/vip receptors in cortical neurons and type i astrocytes. European Journal of Neuroscience 1999, 11, 2767-2772.

41. Lee, M.; Lelièvre, V.; Zhao, P.; Torres, M.; Rodriguez, W.; Byun, J.-Y.; Doshi, S.; Ioffe, Y.; Gupta, G.; De Los Monteros, A.E. Pituitary adenylyl cyclase-activating polypeptide stimulates DNA synthesis but delays maturation of oligodendrocyte progenitors. Journal of Neuroscience 2001, 21, 3849-3859.

42. Yang, J.; Shi, Q.-D.; Song, T.-B.; Feng, G.-F.; Zang, W.-J.; Zong, C.-H.; Chang, L. Vasoactive intestinal peptide increases vegf expression to promote proliferation of brain vascular endothelial cells via the camp/pka pathway after ischemic insult in vitro. Peptides 2013, 42, 105-111.

43. Bellinger, D.L.; Lorton, D.; Brouxhon, S.; Felten, S.; Felten, D.L. The significance of vasoactive intestinal polypeptide (vip) in immunomodulation. Advances in neuroimmunology 1996, 6, 5-27.

44. De la Fuente, M.; Delgado, M.; Gomariz, R.P. Vip modulation of immune cell functions. Advances in neuroimmunology 1996, $6,75-91$.

45. Ganea, D. Regulatory effects of vasoactive intestinal peptide on cytokine production in central and peripheral lymphoid organs. Advances in neuroimmunology 1996, 6, 61-74.

46. Martínez, C.; Delgado, M.; Pozo, D.; Leceta, J.; Calvo, J.R.; Ganea, D.; Gomariz, R.P. Vasoactive intestinal peptide and pituitary adenylate cyclase-activating polypeptide modulate endotoxin-induced il-6 production by murine peritoneal macrophages. Journal of leukocyte biology 1998, 63, 591-601.

47. Delgado, M.; Ganea, D. Neuroprotective effect of vasoactive intestinal peptide (vip) in a mouse model of parkinson's disease by blocking microglial activation. The FASEB journal 2003, 17, 944-946.

48. Delgado, M.; Ganea, D. Vasoactive intestinal peptide prevents activated microglia-induced neurodegeneration under inflammatory conditions: Potential therapeutic role in brain trauma. The FASEB journal 2003, 17, 1922-1924.

49. Sokołowska, P.; Dejda, A.; Nowak, J. Neuroprotective role of pacap, vip, and phi in the central nervous system. Postepy higieny i medycyny doswiadczalnej (Online) 2004, 58, 416-427.

50. Henn, A.; Lund, S.; Hedtjärn, M.; Schrattenholz, A.; Pörzgen, P.; Leist, M. The suitability of bv2 cells as alternative model system for primary microglia cultures or for animal experiments examining brain inflammation. ALTEX: Alternatives to animal experimentation 2009, 26, 83-94.

51. Cheng, H.-H.; Ye, H.; Peng, R.-P.; Deng, J.; Ding, Y. Inhibition of retinal ganglion cell apoptosis: Regulation of mitochondrial function by pacap. Neural regeneration research 2018, 13, 923.

52. Juhász, T.; Matta, C.; Katona, É.; Somogyi, C.; Takács, R.; Gergely, P.; Csernoch, L.; Panyi, G.; Tóth, G.; Reglődi, D. Pituitary adenylate cyclase activating polypeptide (pacap) signalling exerts chondrogenesis promoting and protecting effects: Implication of calcineurin as a downstream target. PloS one 2014, 9, e91541.

53. Scuderi, S.; D’Amico, A.G.; Castorina, A.; Imbesi, R.; Carnazza, M.L.; D’Agata, V. Ameliorative effect of pacap and vip against increased permeability in a model of outer blood retinal barrier dysfunction. Peptides 2013, 39, 119-124.

54. Bolaños, J.P.; Almeida, A.; Stewart, V.; Peuchen, S.; Land, J.M.; Clark, J.B.; Heales, S.J. Nitric oxide-mediated mitochondrial damage in the brain: Mechanisms and implications for neurodegenerative diseases. Journal of neurochemistry 1997, 68, 22272240 .

55. Brown, G.C.; Bal-Price, A. Inflammatory neurodegeneration mediated by nitric oxide, glutamate, and mitochondria. Molecular neurobiology 2003, 27, 325-355.

56. Hill, K.E.; Zollinger, L.V.; Watt, H.E.; Carlson, N.G.; Rose, J.W. Inducible nitric oxide synthase in chronic active multiple sclerosis plaques: Distribution, cellular expression and association with myelin damage. Journal of neuroimmunology 2004, 151, 171-179.

57. Tatsch, E.; Bochi, G.V.; da Silva Pereira, R.; Kober, H.; Agertt, V.A.; de Campos, M.M.A.; Gomes, P.; Duarte, M.M.M.F.; Moresco, R.N. A simple and inexpensive automated technique for measurement of serum nitrite/nitrate. Clinical biochemistry 2011, 44, 348-350. 
58. Miller, E.B.; Zhang, P.; Ching, K.; Pugh, E.N., Jr.; Burns, M.E. In vivo imaging reveals transient microglia recruitment and functional recovery of photoreceptor signaling after injury. Proc Natl Acad Sci U S A 2019, 116, 16603-16612.

59. Crippa, M.P. Urokinase-type plasminogen activator. Int J Biochem Cell Biol 2007, 39, 690-694.

60. Reglodi, D.; Tamas, A.; Somogyvari-Vigh, A.; Szanto, Z.; Kertes, E.; Lenard, L.; Arimura, A.; Lengvari, I. Effects of pretreatment with pacap on the infarct size and functional outcome in rat permanent focal cerebral ischemia. Peptides 2002, 23, 2227-2234.

61. Somogyvari-Vigh, A.; Reglodi, D. Pituitary adenylate cyclase activating polypeptide: A potential neuroprotective peptide. Current pharmaceutical design 2004, 10, 2861-2889.

62. Tanaka, K.; Hashimoto, H.; Shintani, N.; Yamamoto, A.; Baba, A. Reduced hypothermic and hypnotic responses to ethanol in pacap-deficient mice. Regulatory peptides 2004, 123, 95-98.

63. Falktoft, B.; Georg, B.; Fahrenkrug, J. Signaling pathways in pacap regulation of vip gene expression in human neuroblastoma cells. Neuropeptides 2009, 43, 387-396.

64. Nishimoto, M.; Miyakawa, H.; Wada, K.; Furuta, A. Activation of the vip/vpac2 system induces reactive astrocytosis associated with increased expression of glutamate transporters. Brain research 2011, 1383, 43-53.

65. Girard, B.M.; May, V.; Bora, S.H.; Fina, F.; Braas, K.M. Regulation of neurotrophic peptide expression in sympathetic neurons: Quantitative analysis using radioimmunoassay and real-time quantitative polymerase chain reaction. Regulatory peptides 2002, 109, 89-101.

66. Martinez, C.; Abad, C.; Delgado, M.; Arranz, A.; Juarranz, M.G.; Rodriguez-Henche, N.; Brabet, P.; Leceta, J.; Gomariz, R.P. Anti-inflammatory role in septic shock of pituitary adenylate cyclase-activating polypeptide receptor. Proceedings of the National Academy of Sciences 2002, 99, 1053-1058.

67. Zeng, N.; Kang, T.; LYU, R.M.; Wong, H.; Wen, Y.; Walsh, J.H.; Sachs, G.; Pisegna, J.R. The pituitary adenylate cyclase activating polypeptide type 1 receptor (pac1-r) is expressed on gastric ecl cells: Evidence by immunocytochemistry and rtpcr. Annals of the New York Academy of Sciences 1998, 865, 147-156.

68. Kojima, M.; Ito, T.; Oono, T.; Hisano, T.; Igarashi, H.; Arita, Y.; Kawabe, K.; Coy, D.H.; Jensen, R.T.; Nawata, H. Vip attenuation of the severity of experimental pancreatitis is due to vpac1 receptor-mediated inhibition of cytokine production. Pancreas 2005, 30, 62-70.

69. Tan, Y.-V.; Abad, C.; Wang, Y.; Lopez, R.; Waschek, J. Vpac2 (vasoactive intestinal peptide receptor type 2) receptor deficient mice develop exacerbated experimental autoimmune encephalomyelitis with increased th1/th17 and reduced th2/treg responses. Brain, behavior, and immunity 2015, 44, 167-175.

70. Delgado, M.; Abad, C.; Martinez, C.; Juarranz, M.; Arranz, A.; Gomariz, R.; Leceta, J. Vasoactive intestinal peptide in the immune system: Potential therapeutic role in inflammatory and autoimmune diseases. Journal of molecular medicine 2002, 80, $16-24$.

71. Lowenstein, C.J.; Padalko, E. Inos (nos2) at a glance. Journal of cell science 2004, 117, 2865-2867.

72. Blasi, E.; Barluzzi, R.; Bocchini, V.; Mazzolla, R.; Bistoni, F. Immortalization of murine microglial cells by a v-raf/v-myc carrying retrovirus. Journal of neuroimmunology 1990, 27, 229-237.

73. Blasi, E.; Mathieson, B.J.; Varesio, L.; Cleveland, J.L.; Borchert, P.A.; Rapp, U.R. Selective immortalization of murine macrophages from fresh bone marrow by a raf/myc recombinant murine retrovirus. Nature 1985, 318, 667.

74. Kingham, P.; Cuzner, M.; Pocock, J. Apoptotic pathways mobilized in microglia and neurones as a consequence of chromogranin a-induced microglial activation. Journal of neurochemistry 1999, 73, 538-547.

75. Loihl, A.K.; Murphy, S. Expression of nitric oxide synthase-2 in glia associated with cns pathology. In Progress in brain research, Elsevier: 1998; Vol. 118, pp 253-267.

76. Dehmer, T.; Lindenau, J.; Haid, S.; Dichgans, J.; Schulz, J.B. Deficiency of inducible nitric oxide synthase protects against mptp toxicity in vivo. Journal of neurochemistry 2000, 74, 2213-2216. 
77. Parmentier, S.; Böhme, G.A.; Lerouet, D.; Damour, D.; Stutzmann, J.M.; Margaill, I.; Plotkine, M. Selective inhibition of inducible nitric oxide synthase prevents ischaemic brain injury. British journal of pharmacology 1999, 127, 546-552.

78. Lowenstein, C.J.; Alley, E.W.; Raval, P.; Snowman, A.M.; Snyder, S.H.; Russell, S.W.; Murphy, W.J. Macrophage nitric oxide synthase gene: Two upstream regions mediate induction by interferon gamma and lipopolysaccharide. Proceedings of the National Academy of Sciences 1993, 90, 9730-9734.

79. Xie, Q.; Whisnant, R.; Nathan, C. Promoter of the mouse gene encoding calcium-independent nitric oxide synthase confers inducibility by interferon gamma and bacterial lipopolysaccharide. Journal of Experimental Medicine 1993, 177, 1779-1784.

80. Horvath, R.J.; Nutile-McMenemy, N.; Alkaitis, M.S.; DeLeo, J.A. Differential migration, lps-induced cytokine, chemokine, and no expression in immortalized bv-2 and hapi cell lines and primary microglial cultures. Journal of neurochemistry 2008, $107,557-569$.

81. Leceta, J.; Gomariz, R.P.; Martinez, C.; Abad, C.; Ganea, D.; Delgado, M. Receptors and transcriptional factors involved in the anti-inflammatory activity of vip and pacap. Annals of the New York Academy of Sciences 2000, 921, 92-102.

82. Delgado, M.; Munoz-Elias, E.; Gomariz, R.; Ganea, D. Vip and pacap prevent inducible nitric oxide synthase transcription in macrophages by inhibiting $\mathrm{nf}-\mathrm{\kappa b}$ and interferon regulatory factor 1 activation. J. Immunol 1999, $162,4685$.

83. Ito, D.; Imai, Y.; Ohsawa, K.; Nakajima, K.; Fukuuchi, Y.; Kohsaka, S. Microglia-specific localisation of a novel calcium binding protein, iba1. Molecular brain research 1998, 57, 1-9.

84. Tao, X.; Li, N.; Liu, F.; Hu, Y.; Liu, J.; Zhang, Y.-M. In vitro examination of microglia-neuron crosstalk with bv2 cells, and primary cultures of glia and hypothalamic neurons. Heliyon 2018, 4, e00730.

85. Kreutzberg, G.W. Microglia: A sensor for pathological events in the cns. Trends in neurosciences 1996, 19, 312-318.

86. Cunningham, C.L.; Martínez-Cerdeño, V.; Noctor, S.C. Microglia regulate the number of neural precursor cells in the developing cerebral cortex. Journal of Neuroscience 2013, 33, 4216-4233.

87. Cizkova, D.; Devaux, S.; Le Marrec-Croq, F.; Franck, J.; Slovinska, L.; Blasko, J.; Rosocha, J.; Spakova, T.; Lefebvre, C.; Fournier, I. Modulation properties of factors released by bone marrow stromal cells on activated microglia: An in vitro study. Scientific reports 2014, 4, 7514 .

88. Pocock, J.M.; Kettenmann, H. Neurotransmitter receptors on microglia. Trends in neurosciences 2007, 30, 527-535.

89. Aloisi, F. Immune function of microglia. 2001, 36, 165-179.

90. Karthikeyan, A.; Patnala, R.; Jadhav, S.P.; Eng-Ang, L.; Dheen, S.T. Micrornas: Key players in microglia and astrocyte mediated inflammation in cns pathologies. Curr Med Chem 2016, 23, 3528-3546.

91. Vainchtein, I.D.; Molofsky, A.V. Astrocytes and microglia: In sickness and in health. Trends Neurosci 2020, 43, 144-154.

92. Cunningham, O.; Campion, S.; Perry, V.H.; Murray, C.; Sidenius, N.; Docagne, F.; Cunningham, C. Microglia and the urokinase plasminogen activator receptor/upa system in innate brain inflammation. Glia 2009, 57, 1802-1814.

93. Castorina, A.; Waschek, J.A.; Marzagalli, R.; Cardile, V.; Drago, F. Pacap interacts with pac1 receptors to induce tissue plasminogen activator (tpa) expression and activity in schwann cell-like cultures. PloS one 2015, 10, e0117799.

94. Castorina, A.; D’ Amico, A.; Scuderi, S.; Leggio, G.; Drago, F.; D'Agata, V. Dopamine d3 receptor deletion increases tissue plasminogen activator (tpa) activity in prefrontal cortex and hippocampus. Neuroscience 2013, 250, 546-556. 